\title{
ISOTERMAS DE ADSORÇÃO DE SAIS DE CÁDMIO POR Saccharomyces cerevisiae
}

\author{
Silvana Albertini \\ Farmacêutica-Bioquímica
}

Orientador: Prof. Tit. Dr. LUIZ GONZAGA DO PRADO FILHO

Dissertação apresentada à Escola Superior de Agricultura "Luiz de Queiroz", Universidade de São Paulo, para a obtenção do título de Mestre em Agronomia, Área de Concentração:

Microbiologia Agrícola.

PIRACICABA

Estado de São Paulo - Brasil

Fevereiro - 1999 
Dados Internacionais de Catalogação na Publicação (CIP)

DIVISÃo DE BIBLIOTECA E DOCUMENTAÇÃO - Campus "Luiz de Queiroz"/USP.

\author{
Albertini, Silvana \\ Isotermas de adsorção de sais de cádmio por Saccharomyces cerevisiae / Silvana \\ Albertini. - - Piracicaba, 1999.
}

53p.

Dissertação (mestrado) - - Escola Superior de Agricultura Luiz de Queiroz, 1999. Bibliografia.

1. Acetato 2. Biomassa 3. Cádmio 4. Cloreto 5. Levedura 6. Nitrato 7. Sulfato

8. Unidade de adsorção I. Título

CDD 589.23 


\section{AGRADECIMENTOS}

Ao Prof. Tit. Dr. Luiz Gonzaga do Prado Filho, pela oportunidade e orientação.

À Coordenação do Curso de Pós Graduação em Microbiologia Agrícola da Escola Superior de Agricultura Luiz de Queiroz, ESALQ/USP.

Ao Prof. Elliot Watanabe Kitajima, Coordenador do NAPME - Núcleo de Apoio à Pesquisa em Microscopia Eletrônica, e à Silvania Aparecida Machado.

À Profa. Dra Sônia Piedade, do Departamento de Matemática e Estatística, ESALQ/USP, pela orientação na escolha do tratamento estatístico.

Ao Prof. Dr. Claudio Rosa Gallo, do Departamento de Ciência e Tecnologia Agroindustrial, ESALQ/USP, pela doação da cultura de Saccharomyces cerevisiae.

Ao desenhista-projetista Luiz Carlos Rodrigues do Departamento de Ciência e Tecnologia Agroindustrial, ESALQ/USP, pelos serviços prestados.

Às bibliotecárias Beatriz Helena Giongo, Eliana M. G. Sabino e Midian Gustinelli, ESALQ/USP, pelos serviços prestados.

A todos que direta ou indiretamente contribuíram para realização deste trabalho. 


\section{SUMÁRIO}

Página

LISTA DE TABELAS ...................................................... vi

LISTA DE FIGURAS....................................................... vii

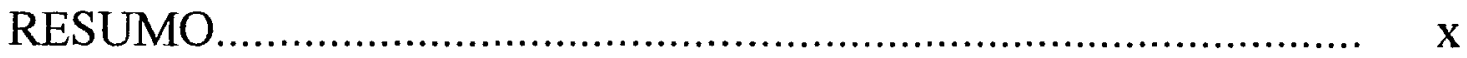

SUMMARY ...................................................................

1. INTRODUÇÃ O.............................................................. 1

2. REVISÃO DE LITERATURA.......................................... 3

2.1. Cádmio....................................................................... 5

2.1.1. Fontes de cádmio nos alimentos...................................... 7

2.1.2. Exposição................................................................... 9

2.1.3. Sinais e Sintomas..................................................... 10

2.1.4. Absorção.................................................................. 11

2.1.5. Distribuição................................................................ 13

2.1.6. Eliminação.................................................................. 13

2.1.7. Mecanismos de toxicidade............................................. 14

2.2. Leveduras como.portadoras de subșancias tóxicas................. 15

2.2.1. Resistência da parede celular das leveduras.......................... 17 
2.2.2. Potencial de biosorção de metais pelas leveduras..................... 18

2.2.3. Técnicas de bioacumulação seletiva de metais....................... 20

2.2.4. Transporte de soluto pela membrana citoplasmática............... 22

3. MATERIAL E MÉTODOS................................................. 24

3.1. Material....................................................................... 24

3.1.1. Levedura utilizada...................................................... 24

3.1.2. Meio de cultura....................................................... 24

3.1.3. Sais de cádmio............................................................ 24

3.2. Métodos....................................................................... 25

3.2.1. Planejamento estatístico do experimento............................. 25

3.2.2. Produção de biomassa.................................................... 25

3.2.3. Determinação da viabilidade celular..................................... 25

3.2.4. Separação da biomassa ................................................. 26

3.2.5. Determinação da matéria seca........................................... 26

3.2.6. Contato biomassa-solução de cádmio................................... 26

3.2.7. Determinação dos pontos da isoterma de adsorção.................. 26

3.2.8. Exame da integridade da parede celular............................. 27

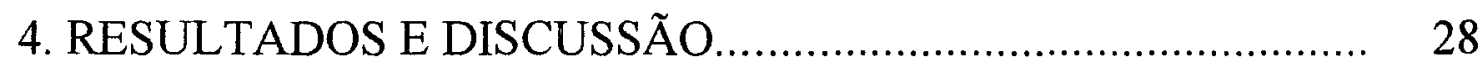

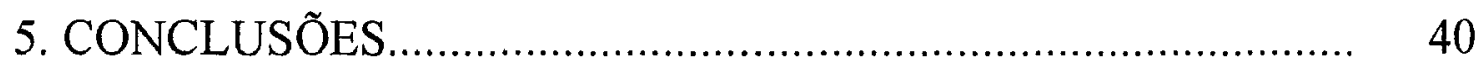


REFERÊNCIAS BIBLIOGRAFIAS ....................................... 41

APÊNDICE …............................................................ 48 


\section{LISTA DE TABELAS}

\section{Página}

1. Concentrações de cádmio adsorvido por Saccharomyces cerevisiae quando colocada em contato com soluções salinas de acetato, cloreto, sulfato e nitrato de cádmio........................... 


\section{LISTA DE FIGURAS}

\section{Página}

1. Isotermas de adsorção de sais de cádmio por Saccharomyces cerevisiae

2. Células de Saccharomyces cerevisiae após contato por 16 h à 26 $28{ }^{\circ} \mathrm{C}$ com água deionizada.

3. Células de Saccharomyces cerevisiae após contato com soluções de $5,10,20$ e $40 \mathrm{mg} \mathrm{L}^{-1}$ de acetato de cádmio por $16 \mathrm{~h}$ à $26-28$ ${ }^{\circ} \mathrm{C}$

4. Células de Saccharomyces cerevisiae após contato com soluções de 60,80 e $100 \mathrm{mg} \mathrm{L}^{-1}$ de acetato de cádmio por $16 \mathrm{~h}$ à $26-28$ ${ }^{\circ} \mathrm{C}$

5. Células de Saccharomyces cerevisiae após contato com soluções de $5,10,20$ e $40 \mathrm{mg} \mathrm{L}^{-1}$ de cloreto de cádmio por $16 \mathrm{~h}$ à $26-28$ ${ }^{\circ} \mathrm{C}$

6. Células de Saccharomyces cerevisiae após contato com soluções de 60,80 , e $100 \mathrm{mg} \mathrm{L}^{-1}$ de cloreto de cádmio por 16 h à $26-28$ ${ }^{\circ} \mathrm{C}$ 
7. Células de Saccharomyces cerevisiae após contato com soluções de $5,10,20$ e $40 \mathrm{mg} \mathrm{L}^{-1}$ de sulfato de cádmio por $16 \mathrm{~h}$ à $26-28$ ${ }^{\circ} \mathrm{C}$.

8. Células de Saccharomyces cerevisiae após contato com soluções de 60,80 , e $100 \mathrm{mg} \mathrm{L}^{-1}$ de sulfato de cádmio por $16 \mathrm{~h}$ à $26-28$ ${ }^{\circ} \mathrm{C}$.

9. Células de Saccharomyces cerevisiae após contato com soluções de $5,10,20$ e $40 \mathrm{mg} \mathrm{L}^{-1}$ de nitrato de cádmio por $16 \mathrm{~h}$ à $26-28$ ${ }^{\circ} \mathrm{C}$

10. Células de Saccharomyces cerevisiae após contato com soluções de 60,80 , e $100 \mathrm{mg} \mathrm{L}^{-1}$ de nitrato de cádmio por $16 \mathrm{~h}$ à $26-28$ ${ }^{\circ} \mathrm{C}$ 


\section{ISOTERMAS DE ADSORÇÃO DE CÁDMIO POR Saccharomyces cerevisiae}

Autora: SLLVANA ALBERTINI

Orientador: Prof. Tit. Dr. LUIZ GONZAGA DO PRADO FILHO

\section{RESUMO}

Com o objetivo de determinar as isotermas de adsorção de cádmio por Saccharomyces cerevisiae, foram utilizados os sais acetato, cloreto, sulfato e nitrato nas concentrações de $5 ; 10 ; 20 ; 40 ; 60 ; 80$ e $100 \mathrm{mg} \mathrm{L}^{-1}$. A biomassa foi produzida a partir de uma cultura starter de Saccharomyces cerevisiae IZ 1904. Após o contato de 16 h, a biomassa foi separada por centrifugação e o teor de cádmio residual foi determinado no sobrenadante por espectrofotometria de absorção atômica. Para os quatro sais empregados foi observado um acúmulo crescente de cádmio nas concentrações de $5 ; 10$;

20 e $40 \mathrm{mg} \mathrm{L}^{-1}$. Nas concentrações de 60;80 e $100 \mathrm{mg} \mathrm{L}^{-1}$ foi observado um decréscimo do acúmulo do metal, evidenciando danos da parede celular, os quais não são sempre acompanhados de iguais danos da membrana, visualizados por microscopia eletrônica de varredura. 


\section{CADMIUM ADSORPTION ISOTHERMS BY Saccharomyces cerevisiae}

Author: SLVANA ALBERTINI

Adviser: Prof. Tit. Dr. LUIZ GONZAGA DO PRADO FLHO

\section{SUMMURY}

With the objective of determining the isotherms of the adsorption of cadmium for Saccharomyces cerevisiae, the acetate, chloride, sulphate and nitrate salts were used, in the concentrations of $5,10,20,40,60,80$, and $100 \mathrm{mg} \mathrm{L}^{-1}$. The biomass was produced from a starter culture of Saccharomyces cerevisiae IZ 1904. After a $16 \mathrm{~h}$ contact the biomass was separated by a centrifuge and the cadmium residue content was determined at the supernatant by atomic adsorption spectrophotometry. For all four salts used a growing accumulation of cadmium was observed at concentrations of 5, 10, 20, and $40 \mathrm{mg} \mathrm{L}^{-1}$. In the concentrations of $60 ; 80$ and $100 \mathrm{mg} \mathrm{L}^{-1}$ a decreasing of the accumulation of the metal was observed, evidencing damages of the cellular wall, which they are not accompanied always of the same damages of the citoplasmatic membrane, visualized by electronic microscopy of sweeping. 


\section{INTRODUÇÃO}

A identificação do cádmio como elemento químico data de 1817. O primeiro caso descrito de intoxicação por cádmio data de 1858. A toxicidade do cádmio foi logo reconhecida e os sintomas foram descritos primeiramente por Marmé em 1867. Apesar disso, sais de cádmio foram usados como antihelmínticos, antisépticos, acaricidas e nematicidas, tendo sido descritos em várias farmacopéias do início do século 20 (Robards \& Worsfold, 1991).

Devido a uma maior consciência sobre os efeitos ecológicos dos metais tóxicos liberados no ambiente, vêm sendo realizados estudos sobre acumulação de metais sob o ponto de vista da recuperação e/ou remoção dos mesmos. Métodos convencionais para remoção de metais em soluções resultantes do processamento de minérios, incluem precipitação química, oxidação ou redução, troca de íons, filtração, tratamento eletroquímico, tecnologia de membrana e recuperação por evaporação. Métodos alternativos de remoção e/ou recuperação do metal estão sendo empregados com base nas propriedades seqüestrantes de materiais naturais de origem biológica (Volesky, 1990b).

Os metais pesados reagem com macromoléculas e com ligantes presentes nas membranas, o que muitas vezes lhes confere propriedades de bioacumulação, biomagnificação na cadeia alimentar, persistência e, de desencadear distúrbios nos processos metabólicos dos seres vivos. A bioacumulação e biomagnificação se encarregam de transformar concentrações consideradas normais, em concentrações tóxicas para diferentes espécies da biota (Pereira, 1995).

A biomagnificação requer uma maior transferência de contaminante entre os níveis tróficos, via ingestão enquanto a bioacumulação requer uma entrada direta $e$ 
independente para cada nível trófico. A bioacumulação está relacionada ao nível de contaminação ambiental e envolve dois processos em competição, a entrada e a depuração. Os fatores que afetam o balanço entre esses dois processos,e, portanto, a rede de entrada, são as formas físico-químicas do cádmio, a presença de outros metais, o pH, a salinidade e a temperatura do ambiente aquático, a estação, a capacidade de troca de cátion do solo e, as espécies de plantas que imobilizam o cádmio (Robards \& Worsfold, 1991).

Produtos residuais de muitos processos industriais, geralmente, contém significantes concentrações de metais, os quais são danosos ao ambiente, além, de constituirem eventual fonte econômica. A presença de metais tóxicos em tais resíduos constitui um risco ambiental, particularmente porque o contínuo decréscimo no $\mathrm{pH}$ da água das chuvas tornam estes resíduos mais lixiviáveis e a contaminação da água mais provável (Natansohn et al, 1992).

A utilização de biomassa microbiana residual, produzida industrialmente, pode ser uma via econômica de material adsorvente de metal. Como produto residual de fermentações industriais, Saccharomyces cerevisiae poderia ser obtida em grandes quantidades e a baixo custo, suprindo uma fonte viável para aplicação em larga escala nos processos de remediação (Brady et al, 1994; Brady \& Dunkan, 1994; Holan \& Volesky, 1994).

O presente trabalho tem por objetivo determinar as isotermas de adsorção de sais de cádmio por biomassa viva de Saccharomyces cerevisiae quando posta em contato com soluções de acetato, cloreto, sulfato e nitrato de cádmio, nas concentrações de 5 , $10,20,40,60,80,100 \mathrm{mg} \mathrm{Cd} \mathrm{L}^{-1}$ de água deionizada. 


\section{REVISÃO DA LITERATURA}

A importância do controle de qualidade para abastecimento público tem crescido pois, o aumento populacional contribuiu para degradação dos mananciais ou postos de captação. No entanto, o desenvolvimento das ciências físicas, químicas e biológicas contribuíram decisivamente para obtenção de novos métodos de controle e tratamento das águas (Macêdo, 1995).

Todo efluente urbano tem como destino final seu encaminhamento a um corpo d'água. Consequentemente, podem surgir inconvenientes como maus odores, sabor estranho, mortandade de peixes e outros, comprometendo a saúde pública pela contaminação das águas de abastecimento, dos balneários, dos alimentos e, para fins agropecuários (Imhoff \& Imhoff, 1986).

Elevadas concentrações de metais pesados potencialmente tóxicos na água e em sedimentos estão comumente associados a diversos processos industriais e atividades humanas (Brady et al, 1994; Sandhu, 1992).

A preocupação com o crescimento industrial, responsável pela introdução cada vez maior de diversos metais no ambiente, tem aumentado o interesse de muitos pesquisadores, das mais diversas áreas de conhecimento, pelo estudo da dinâmica e interação desses elementos no meio ambiente. Estes metais tem ocupado posição de destaque na produção científica, especialmente nos últimos 10 anos. Como consequência desta multidisciplinaridade, o termo "metal pesado" tem sido utilizado indiscriminadamente, em alguns casos de forma errônea do ponto de vista químico, podendo até incluir elementos não metálicos, como o selênio.

Para Alloway (1993) o têrmo "metal pesado" é definido como um grupo de metais que estão sendo associados à poluição e à toxicidade, como chumbo, cádmio, 
mercúrio e arsênio, mas também inclui alguns elementos que são essenciais para vida, quando em baixas concentrações, a exemplo do cobre, cobalto, manganês e zinco. Jardim (1983) considera o termo "metal pesado" incorreto, pois, não caracteriza um número definido para os metais da tabela periódica, podendo assim, gerar dúvidas quanto ao seu emprego.

Alguns autores relacionam o termo metal pesado com a densidade específica do elemento químico. Garcia et al (1990) definem uma densidade mínima para estes metais da ordem de 4,5 $\mathrm{g} \mathrm{cm}^{-3}$ enquanto Coker \& Matthews (1983) definem uma densidade de no mínimo $5,0 \mathrm{~g} \mathrm{~cm}^{-3}$

Para Fernandez (1983) os metais pesados são definidos como elementos de alto peso específico, com densidade superior a $5,0 \mathrm{~g} \mathrm{~cm}^{-3}$, perfazendo um total superior a 40 elementos, e apresentam como propriedades: brilho, condutibilidade térmica e elétrica, capacidade de formar ácidos e reagir com bases.

Os metais pesados pertencem ao grupo de elementos cujos ciclos hídricos, geológicos e químicos têm sido grandemente acelerado pelo ser humano. A emissão antropogênica de metais pesados na atmosfera bem como os descartes residuais dos processos antropogênicos liberados diretamente na hidrosfera, têm aumentado. Desta forma tem-se um acúmulo destes metais nos reservatórios naturais (Schindler, 1991).

A biodisponibilidade e a toxicidade destes metais não existem unicamente em função de sua concentração total, mas, estão relacionadas principalmente com as suas presenças nas fases sólida e em solução. Quando em solução, a relativa toxicidade destes metais está geralmente relacionada à sua forma química, tais como íons complexados organicamente, íons trocáveis e íons complexados inorganicamente. No geral, as formas iônicas livres dos metais são relativamente mais tóxicas que as formas complexadas, além de interagirem mais rapidamente que as outras formas presentes em solução. Portanto, o conhecimento das espécies do metal no sistema natural pode ajudar no entendimento do comportamento e biodisponibilidade do mesmo (Sandhu, 1992). 


\subsection{CÁDMIO}

O cádmio é um elemento altamente tóxico e atualmente vem sendo descrito como um dos elementos traço mais perigosos de todos os metais contaminantes dos alimentos e do ambiente do homem, não apenas pelos altos níveis de toxicidade mas também devido à sua larga distribuição e aplicações muito importantes na indústria química e na metalurgia. Foi descoberto por volta de 1817 por Fredrich Stromeyer como uma impureza do carbonato de zinco $\left(\mathrm{ZnCO}_{3}\right)$. Apesar de ter sido descoberto há mais de um século, foi somente na década de 40, após a Segunda Guerra Mundial que sua aplicação industrial foi bastante difundida em função do crescente desenvolvimento tecnológico. No entanto, os efeitos altamente tóxicos decorrentes de seu uso já haviam sido experimentados pelos humanos há muitos séculos com a ocorrência dos casos de envenenamento por zinco, metal com o qual o cádmio é frequentemente encontrado associado (Reilly, 1991).

O extremo perigo resultante da ingestão de cádmio foi trazido à atenção do mundo com o trágico caso da doença "itai-itai" deflagrada no Japão no final da década de 60 (Adriano, 1986; Reilly, 1991).

Com peso atômico de 112,411 e potencial iônico igual a 2 , o cádmio é o elemento $\mathrm{n}^{\circ} 48$ da tabela periódica, pertencente ao grupo IIB (estado de oxidação igual a 2) juntamente com zinco $(\mathrm{Zn})$ e mercúrio $(\mathrm{Hg})$. Em ordem de abundância é o $67^{\circ}$ elemento da crosta terrestre, com concentração variando de $0,15-0,20 \mathrm{mg} \mathrm{Kg}^{-1}$, distribuído como sulfeto, ou óxido (Mattiazzo-Prezotto,1994). Trata-se de um metal medianamente denso (gravidade específica igual $8,65 \mathrm{~g} \mathrm{~cm}^{3}$ ), de coloração branco prateada, maleável, facilmente cortado com faca e, embora, oxide rapidamente quando exposto à umidade, é bastante resistente à corrosão. Apresenta ponto de fusão igual a 
$320,9{ }^{\circ} \mathrm{C}$ e ponto de ebulição igual a $765{ }^{\circ} \mathrm{C}$, sendo altamente volátil quando aquecido acima de $500{ }^{\circ} \mathrm{C}$. É solúvel em água e compostos orgânicos, incluindo acetato, cloreto e sulfato. É insolúvel na forma de óxido (Adriano, 1986; Reilly, 1991).

Embora o sulfeto de cádmio ocorra naturalmente como um minério amarelo conhecido como "greenockite", este não é comercialmente explorável. O metal é obtido como subproduto na extração e refinamento de outros metais com os quais está naturalmente associado. Zinco é o principal metal com o qual o cádmio ocorre, sendo que as principais fontes são encontradas sob a forma de sulfeto de zinco ( $\mathrm{ZnS}$ ) esfarelita e wurtizita, em proporções que podem variar de $0,2-0,4 \% \mathrm{Cd}$, em função da similaridade na estrutura iônica e eletronegatividade (Reilly, 1991; Tavarez, 1990).

$\mathrm{O}$ cádmio pode também ser encontrado associado ao cobre e chumbo, bem como a grupos contendo - $\mathrm{SH}$, com o qual tem grande afinidade. Antigamente o cádmio era empregado no revestimento de recipientes destinados ao acondicionamento de alimentos e bebidas, porém, o grande número de incidentes de envenenamento por alimentos estocados em recipientes desta natureza alertaram as autoridades quanto a toxicidade do revestimento e atualmente o metal não é mais empregado para esta finalidade.

A participação do cádmio associado ao zinco reduziu notadamente de cerca de $100 \mathrm{mg} \mathrm{Kg}^{-1}$ para menos de $10 \mathrm{mg} \mathrm{Kg}^{-1}$ nos dias de hoje (Reilly, 1991). A produção mundial é relativamente pequena, em torno de 2000 ton ano $^{-1}$, mas vem aumentando em virtude das novas aplicações industriais (Volesky, 1990a). Cerca de $34 \%$ do consumo total de cádmio é aplicado em revestimentos metálicos, aos quais fornece proteção catódica, tornando-os altamente resistentes à corrosão alcalina e marinha. Os principais usuários são a indústria automobilística, espacial e de telecomunicações. A segunda maior aplicação, cerca de $23 \%$ do consumo total de cádmio é como pigmentos para tintas, vernizes e plásticos com base de sulfeto e sulfoselenito de cádmio de coloração variando de amarelo a marron. Outra aplicação importante do cádmio é na indústria de PVC e plásticos afins, onde $15 \%$ do consumo total de cádmio é utilizado como estabilizador, inibindo a degradação do PVC. Ainda que em menores proporções, o 
cádmio apresenta aplicações bastante variadas como componente de acumuladores alcalinos, constituinte de soldas e ligas de baixa fusão, produção de cabos de alta condutividade, como bastão de controle nos reatores nucleares, como endurecedor para cobre, na cura da borracha, na indústria de vidro, na fotografia, litografia e processo de gravura (Mattiazzo-Prezotto, 1994).

O cádmio também é empregado em odontologia como constituinte de amálgama na proporção de $25 \%$ cádmio para $75 \%$ mercúrio e como antihelmíntico para porcos e galinhas na proporção de 0,003\% a 0,1\% (Mattiazzo-Prezotto, 1994). Sais de cádmio foram descritos em várias farmacopéias do início do século 20 por serem utilizados como antihelmínticos, antissépticos, acaricidas e nematicidas (Robards \& Worsfold, 1991).

\subsubsection{FONTES DE CÁDMIO NOS ALIMENTOS}

Apesar de estar presente em quantidades preocupantes na água, no ar e no solo, são os alimentos a principal via de entrada do cádmio no organismo humano, considerando-se indivíduos isentos de exposição ocupacional bem como não fumantes (Elpo \& Freitas, 1995; Pacyna, 1996; Muller et al, 1996).

O Comitê do Codex Alimentarius sobre Contaminantes e Aditivos nos Alimentos propôs níveis de cádmio de $0,1 \mathrm{mg} \mathrm{Kg}^{-1}$ para vegetais e $0,05 \mathrm{mg} \mathrm{Kg}^{-1}$ para os cereais e seus derivados (FAO/WHO, 1989). De acordo com a legislação brasileira, os valores máximos permitidos para o cádmio nos alimentos (e) da ordem de $1,00 \mathrm{mg} \mathrm{L}^{-1}$ (Organização Andrei,1979).

O cádmio industrial também é fonte de contaminação nos alimentos, principalmente de cereais. Ocorrência deste tipo se deu no Japão onde a produção de arroz em áreas poluídas apresentou aproximadamente $1 \mathrm{mg} \mathrm{Kg}^{-1}$, comparada com níveis 
de $0,05-0,07 \mathrm{mg} \mathrm{Kg}^{-1} \mathrm{em}$ áreas não poluídas. Tal contaminação foi atribuída à liberação de cádmio das minas de metais não ferrosos e fundições (Reilly, 1991).

Peixes e outros produtos marinhos, provenientes de águas poluídas geralmente apresentam altos níveis de cádmio. No Japão onde a entrada diária de cádmio na dieta é da ordem de $60 \mu \mathrm{g}$, cerca de $33,66 \%$, ou seja, $21,4 \mu \mathrm{g}$ são devidos ao consumo de peixes e alimentos marinhos (Reilly, 1991). Moluscos, como por exemplo as ostras, são considerados concentradores de cádmio e apresentam valores que variam de 0,1 - 4,7 $\mathrm{mg} \mathrm{Kg}{ }^{-1}$. Da mesma forma, altos valores de cádmio também podem ser encontrados no figado e rins de mamíferos, os quais são da ordem de $0,2-1,3 \mathrm{mg} \mathrm{Kg}^{-1}$ (MattiazzoPrezotto, 1994).

A água normalmente tem uma contribuição mínima para a entrada de cádmio na dieta. Os níveis são geralmente menores que $1 \mu \mathrm{g} \mathrm{L}^{-1}$. No entanto, a contaminação pode ocorrer pelo uso de placas, telhas, canos e cisternas de zinco galvanizado e, assim, resultar em excessiva concentração de cádmio na água. Análises da água utilizada nos aquecedores de hospitais escoceses determinaram níveis de cádmio de até $21 \mu \mathrm{g} \mathrm{L}^{-1}$, quando o valor padrão determinado pela WHO (World Health Organization) é de $10 \mu \mathrm{g}$ $\mathrm{L}^{-1}$

A Lei Estadual n ${ }^{0} 997$ de 31 de maio de 1976, que dispõe sobre a prevenção e controle da poluição no meio ambiente, divide os recursos hídricos em quatro classes distintas:

Classe 1- Pertencem a esta classe as águas destinadas ao abastecimento doméstico que não receberam tratamento prévio nem tão pouco simples desinfecção. Nesta classe não é permitido o lançamento de efluentes mesmo que tratados.

Classe 2- A esta classe pertencem as águas destinadas ao abastecimento doméstico previamente tratadas por método convencional, as águas destinadas à irrigação de hortaliças ou de plantas frutíferas, bem como as águas destinadas à recreação de contato primário como natação e mergulho. Nesta classe é permitido o lançamento de efluentes com no máximo $0,01 \mathrm{mg} \mathrm{L}^{-1}$ de cádmio. 
Classe 3 - Aqui estão classificadas as águas destinadas ao abastecimento doméstico previamente tratadas por método convencional, as águas destinadas à preservação de peixes em geral e de outros elementos da flora e da fauna, bem como as águas destinadas à dessedentação de animais. Nesta classe não é permitido o lançamento de efluentes com quantidades maiores que $0,01 \mathrm{mg} \mathrm{L}^{-1}$ de cádmio.

Classe 4- Encontram-se nesta classe as águas destinadas ao abastecimento doméstico previamente tratada por método avançado, as águas destinadas à navegação, à harmonia paisagística, ao abastecimento industrial, à irrigação e a usos menos exigentes. Nesta classe não é permitido o lançamento de efluentes com quantidades maiores que $0,2 \mathrm{mg} \mathrm{L}^{-1}$ de cádmio. (São Paulo)

Estudos realizados por Muller et al (1996), envolvendo adultos alemães, oralmente expostos ao cádmio por meio de gêneros alimentícios, bebidas e água, constataram que as frutas, leite e subprodutos, açúcar e produtos ricos em açúcar, assim como as bebidas apresentaram conteúdo médio de cádmio $\leq 5 \mathrm{ng} \mathrm{g}^{-1}$ de matéria fresca. $\mathrm{Na}$ carne de boi foi encontrado em media $5,4 \mathrm{ng} \mathrm{g}^{-1}$ e na carne de porco 2,5 $\mathrm{ng} \mathrm{g}^{-1}$. A maioria dos vegetais, incluindo as batatas apresentaram concentrações de cádmio $<25$ $\mathrm{ng} \mathrm{g}^{-1}$. Os pães, bolos, massas e os produtos farináceos, apresentaram cádmio na faixa de 20 - $40 \mathrm{ng} \mathrm{g}^{-1}$. A água potável apresentou uma concentração média de cádmị de $0,2 \mu \mathrm{g}$ $\mathrm{L}^{-1}$.

\subsubsection{EXPOSIÇÃO}

As principais vias de exposição ao cádmio podem ser identificadas como: intensa exposição ocupacional, envolvendo principalmente inalação de poeira e fumaça; ocasional, incluindo a entrada oral de cádmio ou a exposição a este elemento; crônica, na população em geral através dos alimentos, ar e água. Atualmente os casos de 
intoxicação pelo cádmio são relativamente raros, embora, ocasionalmente, se observe intoxicações respiratórias (Robards \& Worsfold, 1991).

A administração de simples dose oral de cádmio em humanos adultos, capaz de não produzir efeito algum é $3 \mathrm{mg} \mathrm{Kg}^{-1}$. Níveis letais são da ordem de $350-500 \mathrm{mg} \mathrm{Kg}^{-1}$, enquanto a concentração letal de fumaça de óxido de cádmio para homens tem sido estimada em $5 \mathrm{mg} \mathrm{m}^{-3}$ para um tempo de exposição de 8h (Pereira, 1995; Robards \& Worsfold, 1991). No fígado, a concentração crítica de cádmio é da ordem de $30-60 \mathrm{mg}$ $\mathrm{Kg}^{-1}$ (Robards \& Worsfold, 1991).

\subsubsection{SINAIS E SINTOMAS}

Longos períodos de ingestão de cádmio acarretam sérios danos renais e doenças ósseas, podendo chegar ao colapso do esqueleto. Tais sintomas foram detectados na notória doença "itai - itai", deflagrada em Jintzu, região do Japão, em decorrência da descarga de resíduos de minérios contendo cádmio diretamente no corpo d'água usado para irrigação dos arrozais (Reilly, 1991; Robards \& Worsfold, 1991), sendo a maioria dos pacientes mulheres em fase de pós menopausa. Esta similaridade de sintomas também

pode ser observada em trabalhadores industriais cronicamente expostos (Nogawa \& Kido, 1996).

A "itai-itai" é uma osteomalacia resultante da combinação de distúrbios metabólicos e disfunção tubular renal, a qual pode ser incrementada pela ingestão inadequada de cálcio (Reilly, 1991). Inicialmente a doença se manifesta através de dores nas costas e pernas, pressão nos ossos longos das pernas e, costelas. Com o decorrer da doença sítios dolorosos espalham-se gradualmente por todo o corpo e a mesma vai se intensificando até um ponto em que mesmo leves encontrões e pancadas levam a 
fraturas dos ossos. Estas condições severas continuam por muitos anos, após os quais o paciente permanece confinado à cama, ficando impossibilitado de dormir e apresentando restrições dos movimentos respiratórios. Consequentemente, o paciente apresenta-se subnutrido e com redução de altura, sendo que nos casos mais severos a altura pode ser reduzida em até $30 \mathrm{~cm}$ (Nogawa \& Kido, 1996).

Sinais de nefrotoxicidade são evidenciados pela presença de proteínas séricas de baixo peso molecular na urina, especialmente $\beta-2$ microglobulina. A hiperexcreção de cálcio e de fósforo podem ocorrer simultâneamente, prejudicando o metabolismo destes minerais ósseos e, desta forma, conduzir à osteomalácia e à osteoporose. Efeitos testiculares amenos também podem ocorrer, porém, a hepatotoxicidade ocorre apenas com doses superiores às que produzem nefrotoxicidade (Robards $\&$ Worsfold, 1991).

$\mathrm{O}$ cádmio não tem função biológica conhecida, sendo considerado extremamente tóxico mesmo em baixas concentrações. No entanto, é encontrado no sangue com concentração variando entre $0,1 \mu \mathrm{g} \mathrm{L}^{-1}$ e $0,3-1,0 \mu \mathrm{g} \mathrm{L}^{-1}$, sendo responsável pela inibição das funções da metalotionina cuja carência acarreta retardo no crescimento humano e, insônia (Cooke \& Johnson, 1996).

\subsubsection{ABSORÇÃO}

Considerando a fumaça do tabaco uma fonte de contaminação, foi determinado que cada unidade de cigarro apresenta um teor aproximado de $1,2 \mu \mathrm{g}$ de cádmio, e que do total de cádmio inalado pela fumaça do tabaco apenas $10 \%$ é absorvido (Gerhardsson \& Skerfving, 1996). As estimativas de Reilly (1991) estabeleceram que cada unidade de

cigarro contém cerca de $0,9-2,0 \mu \mathrm{g} \mathrm{g}^{-1}$ (peso seco) de cádmio e que para cada 20 cigarros fumados $0,5-2,0 \mu \mathrm{g}$ de cádmio podem ser absorvidos por esta via. 
Em condições normais a absorção de cádmio pelo trato gastrointestinal é cerca de $5 \%$ do total ingerido, entretanto, esta percentagem pode variar em função das condições do organismo. Dietas pobres em cálcio e ferro podem ocasionar uma absorção mais elevada, assim indivíduos com deficiência em ferro podem absorver até $20 \%$ do total ingerido (Gerhardsson \& Skerfving, 1996); da mesma forma baixos teores de proteína, zinco, cobre e vitamina D podem ter efeitos similares (Cooke \& Johnson, 1996).

No organismo, o cádmio é retido principalmente pela proteína de baixo peso molecular, a metalotionina. Esta proteina está envolvida no transporte e armazenamento seletivo de uma variedade de metais, podendo reter até $11 \%$ do total de metais ingeridos. O cádmio e o zinco e, em menor extenção, o ferro, o mercúrio e o cobre competem por sítios na metalotionina, a qual é rica em grupamentos sulfidrila (Reilly, 1991).

A metalotionina é produzida pelo figado, mucosa gastrointestinal e córtex renal como resposta à presença do metal (Reilly, 1991; Gerhardsson \& Skerfving, 1996; Law, 1996; Cooke \& Johnson, 1996).

Como resultado da eficiente retenção, a meia vida biológica do cádmio é longa, cerca de 40 anos segundo Reilly (1991) e, 26 anos segundo Law (1996), vindo consequentemente a comprometer a saúde, uma vez que mesmo em baixos níveis de exposição, o organismo acumula o metal por toda vida. $O$ tempo de retenção do cádmio em humanos segundo Tavarez \& Carvalho (1992) é de 10 anos enquanto que, para Cooke \& Johnson (1996) o tempo de retenção pode variar numa faixa de 10 - 30 anos. 


\subsubsection{DISTRIBUIÇÃO}

O cádmio é transportado ligado a uma proteína, principalmente metalotionina, sendo os principais sítios de acúmulo do metal a mucosa intestinal, os rins e o figado (Cooke \& Johnson,1996).

O cádmio, após ser absorvido pelo plasma sanguíneo, é encontrado complexado com albumina e outras proteínas de alto peso molecular; o metal penetra nas células sanguíneas e, assim a concentração do mesmo no plasma é muito menor que nos eritrócitos. O cádmio presente no plasma alcança o figado, onde induz a síntese de metalotionina, a proteina de baixo peso molecular que contém a maior proporção de cisteína, portadora de grupos sulfidrilas aos quais o metal é eficientemente ligado, limitando uma pequena fração do complexo a retornar para circulação. Principalmente por causa das proteínas de baixo peso molecular, o complexo Cd-metalotionina presente no plasma é filtrado através dos glomérulos renais e reabsorvido pelo tubulo proximal, onde gradualmente se acumula. Assim, com exposição crônica, o rim é o orgão de maior índice de contaminação pelo cádmio. O complexo Cd-metalotionina é continuamente quebrado pelas enzimas presentes nos lisossomas das células tubulares e, desta forma, o metal livre é liberado no citoplasma induzindo a síntese renal de metalotionina, a qual é novamente ligada ao cádmio e, em seguida, degradada (Gerhardsson \& Skerfving, 1996).

\subsubsection{ELIMINAÇÃO}

O complexo Cd-metalotionina após ser filtrado pelo glomérulo renal é reabsorvido e acumulado nas células do tubulo proximal. Entretanto existe liberação 
destas células na urina, a qual é a maior rota de excreção. A eliminação do cádmio pelos rins é muito baixa $(0,01-0,02 \%$ da carga corporal) e, governa a excreção de todo o corpo; é crescente com a idade e proporcional à carga corporal, apresentando uma meia vida biológica de muitas décadas. Nos rins, o maior nível de cádmio é encontrado no córtex, numa proporção de 1,25 vezes mais que a média presente nos rins como um todo. Ainda que em menor proporção, o cádmio pode, também, ser excretado pelas fezes através da bile e do suco pancreático, sendo encontrado, também, incorporado pelos cabelos. O cádmio pode alcançar o embrião antes do período de formação da placenta, porém, após a formação desta, o metal sofre deposição, ficando sua passagem para o feto limitada (Gerhardsson \& Skerfving,1996).

\subsubsection{MECANISMOS DE TOXICIDADE}

O grau do efeito tóxico pode ser determinado pela capacidade dos tecidos, ou seja, dos rins em sintetizar metalotionina. Pouco se conhece sobre os mecanismos básicos da toxicidade do cádmio. A origem destes mecanismos pode estar na exposição através da respiração, ou ingestão. Sabe-se que o cádmio liga-se aos grupos sulfidrila das proteínas e, quando a ligação ocorre com uma enzima, esta pode ter sua função inibida, resultando em efeitos tóxicos (Gerhardsson \& Skerfving, 1996).

A toxicidade dos metais é uma questão de dose ou tempo de exposição, da forma física e química do elemento e, da via de administração e absorção. Deve ser considerado também que o carater tóxico de uma determinada forma química específica depende da interação com o organismo humano, a qual ocorre em três estágios (Tavares \& Carvalho, 1992):

- entrada e absorção,

- transporte, distribuição, acumulação e biotransformação, 
- eliminação por diferentes vias.

A incidência de toxicidade aguda é rara, embora a inalação da fumaça de cádmio seja um risco industrial bastante conhecido (Cooke \& Johnson, 1996).

Existem evidências de que a toxicidade do cádmio pode ser reduzida pela ingestão simultânea de alguns outros metais como zinco, cobre e selênio. $\mathrm{O}$ cádmio compete com o zinco e outros metais pelos sítios de ligações da metalotionina, indicando que ocorrem interações metabolicamente significantes entre esses elementos. Entretanto, a introdução de pequenas quantidades de cobre na dieta pode levar a uma redução da tolerância ao cádmio (Reilly, 1991).

\subsection{LEVEDURAS COMO PORTADORAS DE SUBSTÂNCIAS TÓXICAS}

Leveduras são fungos unicelulares, eucarióticos, com tamanho variando de 1 - 5 $\mathrm{m} \mu$ em largura e 5 - $30 \mu \mathrm{m}$, ou mais, em comprimento. As espécies apresentam formas características, mas mesmo em uma cultura pura ocorrem variações no tamanho e forma das células, as quais podem ser esféricas, ovóides, elipsóides e filamentosas. Desprovidas de qualquer mecanismo de locomoção, as leveduras crescem em um meio apropriado adicionado de ágar formando colônias lisas e brilhantes (Pelczar, 1996b). Assim como os bolores, as leveduras podem ser benéficas, ou prejudiciais. São causadoras de deterioração em alimentos e de doenças humanas. (Pelczar, 1996a).

As leveduras são conhecidas há muitos séculos pelo ser humano, principalmente por sua habilidade em produzir álcool. Entretanto, foram os estudos realizados por Louis Pasteur (1857 - 1876), que estabeleceram o papel da levedura na transformação do açúcar em álcool (Halász \& Lásztity, 1991b).

A importância da biomassa de levedura sob o ponto de vista industrial reside no fato desta matéria prima ser composta de uma variedade de componentes úteis e, por 
este motivo, ser amplamente utilizada no fabrico de inúmeros produtos. $\mathrm{Na}$ fabricação de novos produtos a partir da biomassa de levedura podem ser empregados apenas alguns componentes celulares, ou a célula toda, sendo o concentrado proteíco e a levedura seca as duas principais formas de aplicação da biomassa (Halász \& Láztity, 1991b). A produção de enzimas, ácidos nucleicos, nucleotídeos, nucleosídeos, lipídeos, vitaminas, carboidratos e muitos outros produtos empregam a biomassa de levedura como matéria prima (Haslász \& Lásztity, 1991a).

Além do conteúdo proteíco, as leveduras podem atuar como portadoras potenciais de substâncias tóxicas, entre as quais podem estar os metais pesados que as leveduras têm capacidade de acumular (Brady \& Dunkan, 1994; Holan \& Volesky, 1995 Volesky, 1990a).

As leveduras apresentam parede celular rígida cuja função é manter a forma da célula e evitar que ela sofra lise por pressão osmótica. Independente da célula eucariótica apresentar parede celular, ela é dotada de uma membrana citoplasmática semipermeável que envolve todo corpo da célula. (Pelczar, 1997b).

O processo de adsorção de íons metálicos por células vivas envolve parâmetros químicos como carga do metal, raio iônico, preferência do metal por ligantes orgânicos, disponibilidade do metal como poluente ambiental ou não e reações químicas dos íons em solução (Wood \& Wang, 1983).

A capacidade que os microrganismos apresentam de acumular metais pesados geralmente envolve duas fases: uma ligação rápida com a superfície celular, independente do metabolismo, seguida de um acúmulo intracelular dependente do metabolismo e com gastos de energia. No acúmulo independente do metabolismo, os cátions podem se depositar por processo de adsorção ou precipitação inorgânica, ou ficarem adsorvidos à grupos aniônicos fixos, presentes na parede celular. (Brady \& Dunkan, 1994; Volesky, 1990b; Volesky \& May-Phillips, 1995).

Por processo independente de energia foi constatado que um grama de levedura morta acumula cerca de 24,7 mg de cádmio (Volesky, 1990b). No acúmulo dependente do metabolismo, o ín metálico é conduzido pelas proteínas de transporte através da 
membrana celular, ficando acumulado no citossol ligado a metalotionina, metaloproteína de baixo peso molecular constituída de cerca de $30 \%$ de cisteína, portadora de grupamentos - $\mathrm{SH}$, com os quais os metais apresentam Brady \& Duncan, 1994). A metalotionina está envolvida no armazenamento de metais, destoxificação, desenvolvimento, diferenciação, controle do metabolismo celular, proteção contra radicais livres tóxicos e resposta à radiação ultra violeta (Brady \& Duncan, 1994; Volesky, 1990b). Segundo os autores essa proteína faz parte da resposta ao estresse agudo para a maioria das células.

\subsubsection{RESISTÊNCIA DA PAREDE CELULAR DAS LEVEDURAS}

É bastante conhecido, também, que um dos mecanismos de resistência de leveduras aos metais pesados é a redução da permeabilidade da parede celular (White \& Gadd, 1986). Assim elevadas concentrações de cádmio, gerando perda de $\mathrm{K}^{+}{\mathrm{e} \mathrm{Mg}^{+2}}^{+2}$ provocam danos irreversíveis e enfraquecimento da membrana celular com posterior rompimento da parede e membrana (Gadd \& Mowll, 1983).

A superfície celular é de fundamental importância na relação entre a célula e o ambiente, sendo a responsável pelo primeiro contato da célula com o ambiente, e, é através dela que os íons metálicos são transportados para o interior da célula. Assim, quando os metais pesados são depositados em um ambiente, eles podem ligar-se à superficie dos microrganismos, o que vem a ser o passo inicial na captura $e$ concentração dos metais pelos mesmos, bem como, nos efeitos tóxicos desses metais (Collins \& Stotzky, 1992). Para os autores a toxicidade de alguns metais pesados para vários microrganismos varia com $\mathrm{o} \mathrm{pH}$, pois a hidrólise forma espécies destes metais que são retidos na superfície celular em pH elevado, alterando assim, a carga líquida da 
célula, o que acarreta danos nas funções fisiológicas da mesma bem como nas interações com outras células e partículas inanimadas.

Para as células de levedura a parede celular é um investimento muito importante visto que mais de $30 \%$ do peso seco da célula é constituído pela mesma. Morfologicamente a parede celular apresenta estrutura em camadas, o que parece ser um fenômeno geral nas leveduras. A camada interna constituída de glucanas, é a responsável pela resistência mecânica da parede celular. A densa camada externa constituída predominantemente de manoproteínas é sensível ao ataque proteolítico e não está diretamente envolvida na manutenção da resistência mecânica da parede celular. É ela quem determina as propriedades superficiais como hidrofobicidade, carga elétrica, floculabilidade, aglutinabilidade sexual, patogenicidade, permeabilidade para macromoléculas e elasticidade. Em função desta propriedade de elasticidade, quando células em crescimento são transferidas para um meio hipertônico, rapidamente se encolhem em comprimento e diâmetro, enquanto o volume diminui em cerca de $50 \%$; a parede celular torna-se mais espessa, mas a membrana plasmática não separa da parede. Quando, subsequentemente, são transferidas para um meio isotônico, as células recuperam o volume original (Klis, 1994).

\subsubsection{POTENCIAL DE BIOSORÇÃO DE METAIS PELAS LEVEDURAS}

A biosorção, capacidade que a célula apresenta em sequestrar passivamente o metal, é causada por um número de diferentes mecanismos físico - químicos e depende de fatores externos ao ambiente bem como do tipo de metal, forma iônica do metal em solução e, do tipo de sítio ativo de retenção responsável pelo sequestramento do metal. Uma característica importante da biosorção é que ela pode ser responsável pela retenção e acumulação metálica mesmo quando a célula não é mais metabolicamente ativa, ou 
seja, quando morta. O potencial de biosorção da biomassa microbiana depende da sua composição química e, pode ser avaliada apenas experimentalmente. Assim, qualquer que seja o mecanismo de retenção do metal pelo material biosorvente, observa-se que os cátions metálicos são atraídos por sítios carregados negativamente, presentes na superfície celular, (Volesky, 1990a).

Uma isoterma de biosorção reflete um processo de equilibrio pelo qual o metal retido pelo biosorvente está em um estado de equilíbrio com as espécies iônicas dissolvidas em solução. Pode levar algum tempo para que este equilíbrio se estabilize, mas quando ocorre, o sistema teoricamente permanece em uma firme condição equilibrada, com uma certa quantia de espécie metálica sequestrada, retida, e imobilizada pela fase sólida do biosorvente, e, uma outra porção do metal permanecendo dissolvida em solução. (Volesky, 1990b).

A biosorção de íons de metais pesados por biomassa morta vem sendo empregada como alternativa para as já existentes tecnologias de remoção aplicadas para tratamento de águas residuais. A utilização de biomassa morta, ou produtos derivados, contorna tanto o problema de toxicidade dos íons metálicos e das condições adversas de operação, quanto o da manutenção e suplementação nutricional para sobrevivência das células (Matis \& Zouboulis, 1994).

$\mathrm{Na}$ adsorção os solutos presentes originariamente na solução, são retidos pela superfície do material sólido e, na absorção o soluto é retido mais no interior do sólido que na sua superfície. Esse processo está relacionado com a membrana e parede celulares das células microbianas e, também, com a produção de exopolímeros pois são essas as estruturas responsáveis pela barreira, transporte e penetração de solutos e solventes na célula (Trindade, 1996).

Vários microrganismos foram testados por Nakajima \& Sakaguchi (1986) para verificar a capacidade em precipitar diferentes metais pesados da solução através da sorção. Ao todo foram testadas 32 bactérias, 15 leveduras como Candida utilis $e$ Saccharomyces cerevisiae, 16 fungos filamentosos e 20 Actinomicetos. Ficou constatado que as linhagens de Bacillus subtilis, Actinomyces flavoridis, Streptomyces 
obiraceus, S. albus, S. diastaticus, S. viridocromogenes e Mucor javanicus, mostraram um nível extremamente alto de adsorção dos metais $\mathrm{Mn}, \mathrm{Co}, \mathrm{Ni}, \mathrm{Cu}, \mathrm{Zn}, \mathrm{Cd}, \mathrm{Hg}, \mathrm{Pb}$ e U.

\subsubsection{TÉCNICAS DE BIOACUMULAÇÃO SELETIVA DE METAIS}

Os mecanismos predominantemente utilizados pelos microrganismos para remoção de metais pesados presentes em águas residuais são as ligações à superfície celular e complexação extracelular com subsequente acumulação. No entanto ficou constatado que a capacidade da levedura promover ligações superficiais com íons metálicos divalentes é relativamente baixa se comparada as algas, bactérias e fungos filamentosos (Volesky, 1990a).

Os estudos realizados por Fukushi et al (1996) para investigar o desempenho de culturas de lodo ativado capazes de remover metais pesados na presença de biopolímeros constataram que cistina, peptona e BGP ( $\beta$ glicerofosfato) estimularam a captura de metais sem reduzir significantemente a viabilidade da cultura quando comparada à captura de metais realizada com culturas sem emprego de biopolímeros. As culturas crescidas na presença do conjunto cistina/peptona/BGP exibiram a maior taxa de remoção de $\mathrm{Cu}$ e Cd (360,3 $\mathrm{mg} \mathrm{g}^{-1}$ e $\left.284,4 \mathrm{mg} \mathrm{g}^{-1}\right)$, respectivamente.

A técnica de bioacumulação seletiva de metais pesados por sistemas microbianos oferece um possível acesso para remediação dos corpos d'água contaminados. Estudos de bioacumulação de metais pesados por Saccharomyces cerevisiae imobilizada em poliacrilamida, evidenciaram que sistemas de bioacumuladores em série permitiram uma maior redução dos níveis de $\mathrm{Cu}, \mathrm{Cd}$ e $\mathrm{Co}$ no efluente final, quando comparado com sistema único de bioacumulador. Outro fato evidenciado foi que mais de um cátion metálico poderia ser acumulado simultâneamente e em grandes quantidades, maiores 
que quando um único metal estava presente no efluente, chegando às seguintes quantidades acumuladas: $\mathrm{Cu}^{+2}=27,32 \mathrm{mg} \mathrm{g}^{-1} ; \mathrm{Cu}^{+2}+\mathrm{Cd}^{+2}=117,88 \mathrm{mg} \mathrm{g}^{-1} ; \mathrm{Cu}^{+2}+$ $\mathrm{Co}^{+2}=101,65 \mathrm{mg} \mathrm{g}^{-1}$ de massa de levedura seca, sendo que a concentração inicial de cada uma das espécies metálicas foi de $12,70 \mathrm{mg} \mathrm{L}^{-1} \mathrm{Cu} ; 22,48 \mathrm{mg} \mathrm{L}^{-1} \mathrm{Cd} ; 11,78 \mathrm{mg} \mathrm{L}^{-1}$ Co (Brady et al, 1994).

O estudo realizado por Brady \& Dunkan (1994) mostrou que celulas de levedura em suspensão acumularam $\mathrm{Cu}^{+2,} \mathrm{Co}^{+2}, \mathrm{Cd}^{+2}$. Os níveis de acumulação foram dependentes da concentração e dos valores extremos de $\mathrm{pH}$ do ambiente. Foi observado também que temperatura na faixa de $5-40^{\circ} \mathrm{C}$ bem como a presença de alcali mostraram pequena influência sobre os niveis de acumulação.

Trabalhos desenvolvidos por Volesky \& Prasetyo (1993) utilizando cádmio para examinar novos materiais biosorventes derivados de algas marinhas marrons Ascophylum nodosum, em colunas de sorção, determinaram uma eficiência no processo de remoção da ordem de $99,985 \%$.

Diferentes tipos de biomassa provenientes de algas marinhas foram analisadas por Holan \& Volesky (1993), as quais revelaram elevada biosorção passiva de chumbo, superior a $270 \mathrm{mg} \mathrm{Pb} \mathrm{g}$ " biomassa. Membros da ordem "FUCALES" apresentaram grande capacidade de biosorção deste metal na sequência: Fucus > Ascophyllum > Sargassum. A biosorção de $370 \mathrm{mg} \mathrm{Pb} \mathrm{g}^{-1}$ na biomassa foi observada quando utilizados conjuntamente Fucus vesiculosus e Ascophyllum nodosum.

Volesky et al (1993) constataram o acúmulo de $17,98 \mathrm{mg} \mathrm{Cd} \mathrm{g}^{-1}$ célula viva de Saccharomyces cerevisiae, enquanto Saccharomyces uvarum e Candida utilis acumularam 14,61 $\mathrm{mg} \mathrm{Cd} \mathrm{g}^{-1}$ célula viva.

O trabalho realizado Volesky \& May-Phillips (1995) para avaliar a capacidade de biomassa de levedura em sequestrar metais pesados presentes em soluções aquosas diluídas constatou que várias espécies de levedura tem habilidade de sequestrar cádmio da solução, o que tem despertado o interesse dos pesquisadores visto ser este um dos três metais altamente tóxicos. Neste experimento foi constatado que para levedura de cervejaria (viva e morta) a biosorção seguiu a ordem $U>\mathrm{Zn}>\mathrm{Cd}>\mathrm{Cu}$. Para levedura 
morta de pão a biosorção foi $\mathrm{Zn}>\mathrm{Cd}>\mathrm{U}>\mathrm{Cu}$ e, para levedura viva de pão foi $\mathrm{Zn}>\mathrm{Cu}$ $=\mathrm{Cd}>\mathrm{U}$.

Estudos realizados por Rammholdt et al (1994) para determinar a concentração de metais pesados em leveduras presentes nos efluentes de destilaria mostrararn que $o$ material bruto é a principal fonte de metais pesados no efluente. Os autores observaram, também, que a concentração do metal não foi alta o suficiente para inibir as leveduras e, que uma quantidade considerável de metais foi capturada pelas leveduras.

Omar et al (1996) concluiram que biomassa de Saccharomyces cerevisiae proveniente de indústrias de cervejaria, como biosorvente de urânio é um importante subproduto passivel de ser usado na purificação de água contaminada com este íon. Os

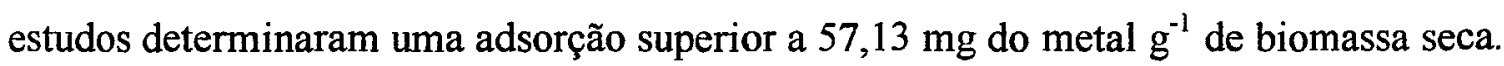
Foi observado também que uma ampla faixa de temperatura, de 10 a $37^{\circ} \mathrm{C}$ não influenciou a adsorção, no entanto, o pH mostrou influência, sendo o valor ideal $\mathrm{pH}=$ 4,5. Uma concentração de urânio de $23,803 \mathrm{~g} \mathrm{~L}^{-1}$ a $119,05 \mathrm{~g} \mathrm{~L}^{-1}$ foi adsorvida de 84 a $98 \%$ por grama de biomassa de levedura seca.

\subsubsection{TRANSPORTE DE SOLUTO PELA MEMBRANA CITOPLAS- MÁTICA}

A membrana citoplasmática é contituída de uma bicamada lipídica com proteínas inseridas que são as responsáveis pelo transporte de soluto de um lado para outro da membrana. Existem dois tipos de proteínas envolvidas no transporte de solutos: as proteínas canais e as proteínas carreadoras. As proteínas canais não necessitam se ligar ao soluto; elas formam poros hidrofilicos que se estendem através da bicamada, e quando abertos, estes poros permitem que solutos específicos passem por eles, atravessando a membrana numa velocidade muito maior do que o transporte mediado 
pelas proteínas carreadoras. As proteínas carreadoras se ligam a um soluto específico a ser transportado, sofrem uma série de mudanças conformacionais promovendo a transferência do soluto a elas ligado através da membrana. As proteínas carreadoras estão subdivididas em três grupos: uniportadoras, simportadoras e antiportadoras. As uniportadoras são as proteínas que transportam um único soluto de um lado para outro da membrana. As simportadoras são as proteínas cuja transferência de um soluto depende da transferência simultânea ou seqüencial de um segundo soluto na mesma direção. As antiportadoras são as proteínas cuja transferência de um soluto depende da transferência simultânea ou seqüencial de um segundo soluto na direção oposta (ALBERTS et al, 1997). 


\section{MATERIAL E MÉTODOS}

\subsection{MATERIAL}

Todos os utensílios utilizados nos experimentos foram previamente lavados e descontaminados (Martin et al, 1992).

\subsubsection{LEVEDURA UTILIZADA}

A levedura utilizada foi Saccharomyces cerevisiae IZ 1904 da coleção de culturas do departamento de Agroindustria, Alimentos e Nutrição - ESALQ/USP.

\subsubsection{MEIO DE CULTURA}

O meio de cultura utilizado para produção de biomassa foi caldo GLT (glucoseextrato de levedura - triptona (Lodder, 1971).

\subsubsection{SAIS DE CÁDMIO}

Os sais de cádmio utilizados na preparação das soluções de contato foram acetato, cloreto, sulfato e nitrato de cádmio, marca Carlo Erba, todos com pureza superior a $99 \%$. 


\subsection{MÉTODOS}

\subsubsection{PLANEJAMENTO ESTATÍSTICO DO EXPERIMENTO}

O experimento foi realizado segundo o delineamento experimental inteiramente casualizado com 4 sais, 7 concentrações e 3 repetições (Gomes, 1990). Os resultados foram analisados pelo programa SANEST (Zonta e Machado, 1992).

\subsubsection{PRODUÇÃO DE BIOMASSA}

A partir de uma cultura estoque de Saccharomyces cerevisiae foi preparada uma cultura "starter" em tubos de ensaio contendo aproximadamente $10 \mathrm{~mL}$ de caldo de cultura GLT (glucose - extrato de levedura - triptona), mantidos a uma temperatura de 21

${ }^{0} \mathrm{C}$ em estufa incubadora para B.O.D. NOVA TÉCNICA NS 705 por 24 horas (Lodder, 1971). A cultura "starter" foi transferida dos tubos de ensaio para erlenmeyers de 500 $\mathrm{mL}$ contendo $200 \mathrm{~mL}$ de caldo de cultura GLT, mantidos sob agitação na faixa de temperatura de $26-28{ }^{\circ} \mathrm{C}$, por 48 horas em agitador orbital PA 141 MARCONI.

\subsubsection{DETERMINAÇÃO DA VIABILIDADE CELULAR}

A viabilidade celular foi determinada segundo Moraes \& Alves (1986). 


\subsubsection{SEPARAÇÃO DA BIOMASSA}

A biomassa produzida foi separada por centrifugação a 1500 gravidades por 15 minutos.

\subsubsection{DETERMINAÇÃO DA MATÉRIA SECA}

A matéria seca foi determinada por processo indireto segundo Silva (1990).

\subsubsection{CONTATO BIOMASSA-SOLUÇÃO DE CÁDMIO}

Dos quatro sais de cádmio (acetato, cloreto, sulfato e nitrato) foram preparadas soluções nas concentrações de $5 ; 10 ; 20 ; 40 ; 60 ; 80$ e $100 \mathrm{mg} \mathrm{L}^{-1}$. Cincoenta mililitros de cada solução foram transferidos, em triplicata, para erlenmeyers de $125 \mathrm{~mL}$. A cada amostra foi adicionado o peso exato de $1,0 \mathrm{~g}$ de levedura úmida. $\mathrm{O}$ contato biomassasolução foi sob agitação excêntrica por um período de 16 horas, à temperatura ambiente de $26-28^{\circ} \mathrm{C}$, conforme o recomendado por Volesky (1990a).

\subsubsection{DETERMINAÇÃO DOS PONTOS DA ISOTERMA DE ADSORÇÃO}

Após o tempo de contato de $16 \mathrm{~h}$, o conjunto biomassa-solução foi centrifugado à 1500 gravidades por 15 minutos, separando-se o sobrenadante, cujo teor de cádmio residual foi determinado por espectrofotometria de absorção atômica, em espectrofotômetro VARIAN modelo AA-175. Por cálculo foi quantificado o cádmio acumulado pela levedura, expressando-se os resultados em $\mathrm{mg} \mathrm{Cd} \mathrm{g}^{-1}$ de matéria seca. 


\subsubsection{EXAME DA INTEGRIDADE DA PAREDE CELULAR}

Amostras de massas celulares obtidas por centrifugação (3.2.6.) foram devidamente preparadas, segundo metodologia descrita por Kitajima (1997), e, examinadas por microscopia eletrônica de varredura em microscópio eletrônico VARIAN ZEISS DSM 940A. 


\section{RESULTADOS E DISCUSSÃO}

Os perfis das isotermas de adsorção de cádmio utilizando-se acetato, cloreto, sulfato e nitrato de cádmio como sais contaminantes são mostradas na figura 1 . As quatro isotermas apresentam perfis qualitativamente semelhantes, porém, quantitativamente diferentes, quando consideradas ponto a ponto.

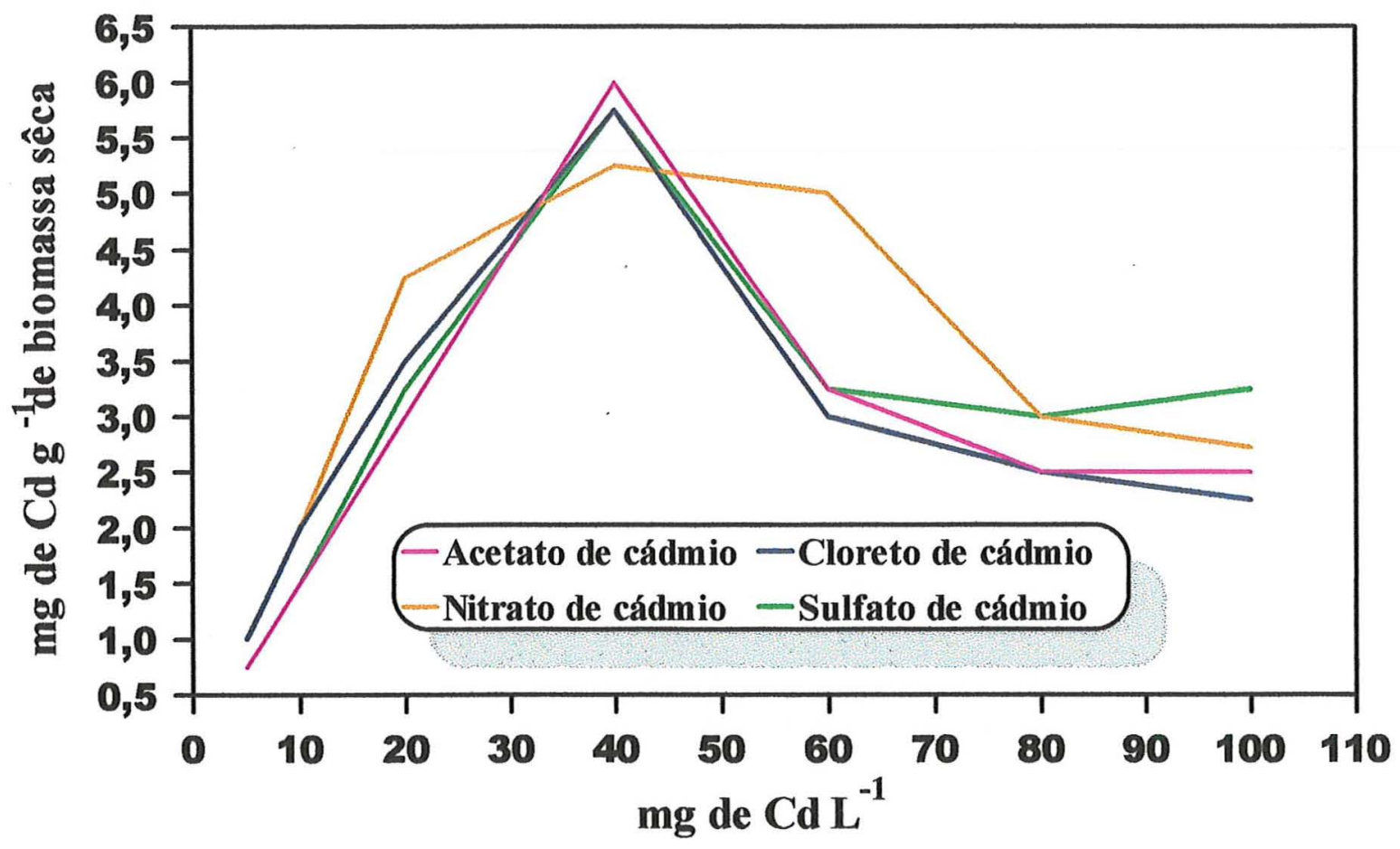

Figura 1. Isotermas de adsorção de sais de cádmio por Saccharomyces cerevisiae.

As diferenças estatísticas, ao nível de $1 \%$, dos teores de cádmio nas diversas concentrações dos quatro sais, em cada concentração estudada, é mostrada na tabela 1. 
As diferenças estatísticas nos teores acumulados, em cada concentração dos sais, demonstra que o sal portador do metal tem influência no acúmulo deste pela levedura. Na concentração de $40 \mathrm{mg} \mathrm{L}^{-1}$ na solução de contato o cádmio do acetato foi acumulado com maior eficiência que o cádmio dos demais sais.

$\mathrm{Na}$ concentração de $60 \mathrm{mg} \mathrm{L}^{-1}$ na solução de contato o cádmio do nitrato potencializa um acúmulo estatísticamente bem superior ao dos outros sais. $\mathrm{Na}$ concentração de $100 \mathrm{mg} \mathrm{L}^{-1}$ a quantidade de cádmio acumulada da solução de contato do nitrato é menor que a propiciada pela solução de contato do sulfato, mas, superior ao do cloreto e acetato.

Tabela 1 - Concentrações de cádmio adsorvido por S. cerevisiae em contato com soluções com diferentes concentrações deste elemento, durante $16 \mathrm{~h}$ à temperatura média de 26 a $28^{\circ} \mathrm{C}$

\begin{tabular}{|c|c|c|c|c|}
\hline $\begin{array}{c}\text { Sais } \\
\text { concentrações } \\
\left(\mathrm{mg} \mathrm{L}^{-1}\right)\end{array}$ & $\begin{array}{c}\mathrm{CdC}_{4} \mathbf{H}_{6} \mathrm{O}_{4} \mathbf{2 H}_{2} \mathrm{O} \\
\mathrm{mg} \mathrm{Cd} \mathrm{g}^{-1} \\
\text { biomassa seca }\end{array}$ & 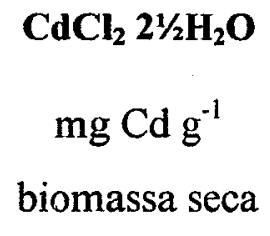 & $\begin{array}{c}\mathbf{3 C d S O}_{4} \mathbf{8 H}_{2} \mathbf{O} \\
\mathrm{mg} \mathrm{Cd} \mathrm{g}^{-1} \\
\text { biomassa seca }\end{array}$ & $\begin{array}{c}\mathrm{Cd}\left(\mathrm{NO}_{3}\right)_{2} \mathbf{4 H}_{2} \mathrm{O} \\
\mathrm{mg} \mathrm{Cd} \mathrm{g}{ }^{-1} \\
\text { biomassa seca }\end{array}$ \\
\hline 5 & $0,75 \mathrm{~B}$ & $0,98 \mathrm{~A}$ & $0,75 B$ & $0,99 \mathrm{~A}$ \\
\hline 10 & $1,50 \mathrm{~B}$ & $1,98 \mathrm{~A}$ & $1,50 \mathrm{~B}$ & $2,00 \mathrm{~A}$ \\
\hline 20 & $3,00 \mathrm{D}$ & $3,42 \mathrm{~B}$ & $3,25 \mathrm{~B}$ & $4,25 \mathrm{~A}$ \\
\hline 40 & $6,00 \mathrm{~A}$ & $5,75 \mathrm{~B}$ & $5,75 \mathrm{~B}$ & $5,27 \mathrm{C}$ \\
\hline 60 & $3,25 \mathrm{~B}$ & $2,98 \mathrm{C}$ & $3,23 \mathrm{~B}$ & $5,00 \mathrm{~A}$ \\
\hline 80 & $2,52 \mathrm{~B}$ & $2,50 \mathrm{~B}$ & $3,00 \mathrm{~A}$ & $3,00 \mathrm{~A}$ \\
\hline 100 & $2,50 \mathrm{C}$ & $2,25 \mathrm{D}$ & $3,25 \mathrm{~A}$ & $2,82 \mathrm{~B}$ \\
\hline
\end{tabular}

As médias, seguidas de uma mesma letra, em uma mesma linha, não diferem entre si segundo Tukey a $1 \%$ de significância. 


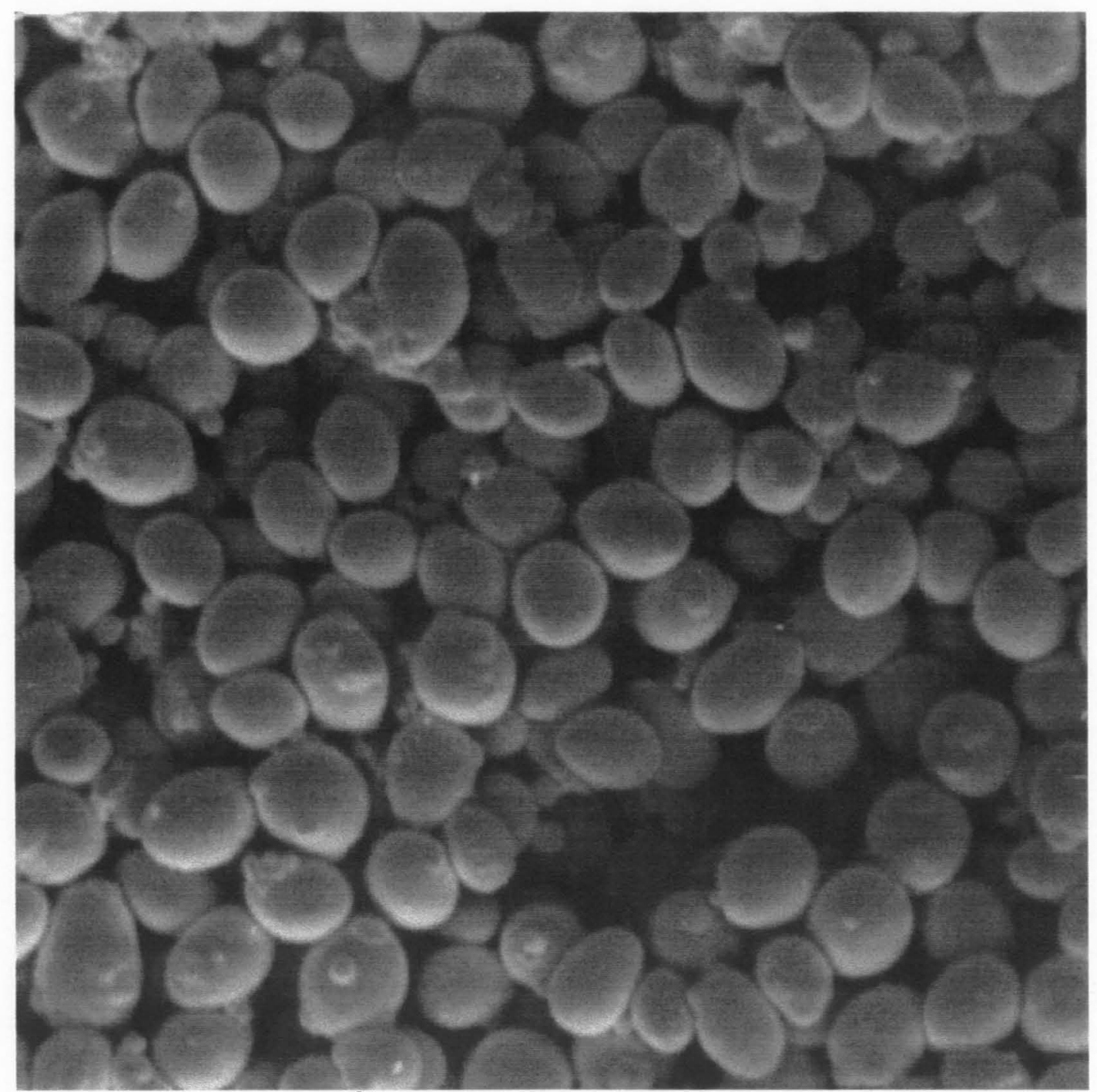

Água deionizada x 3000

Figura 2- Células de $S$. cerevisiae após contato com água deionizada por 16 horas à 26$28^{\circ} \mathrm{C}$. Água deionizada $x$ seguido de número $=$ aumento empregado na microscopia eletrônica por varredura. 


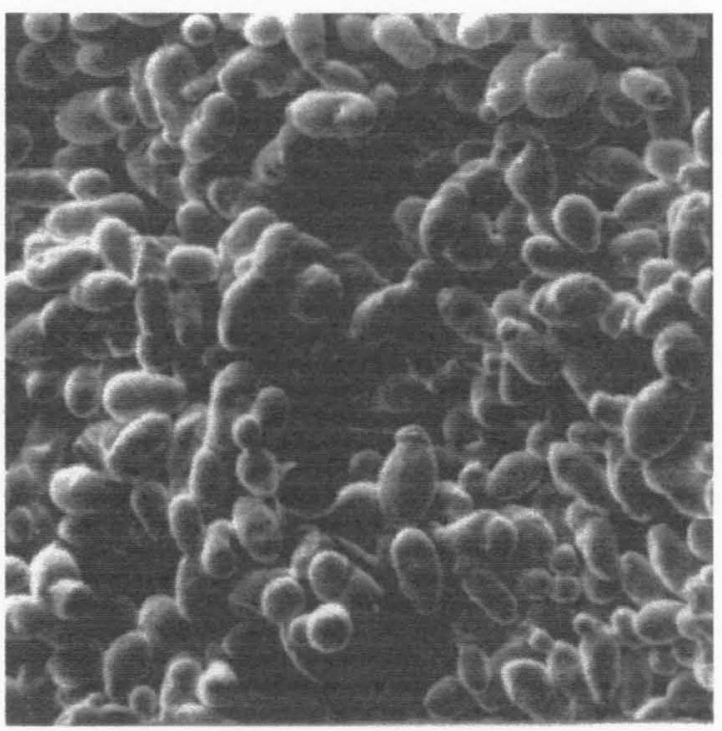

Ac5 x 2700

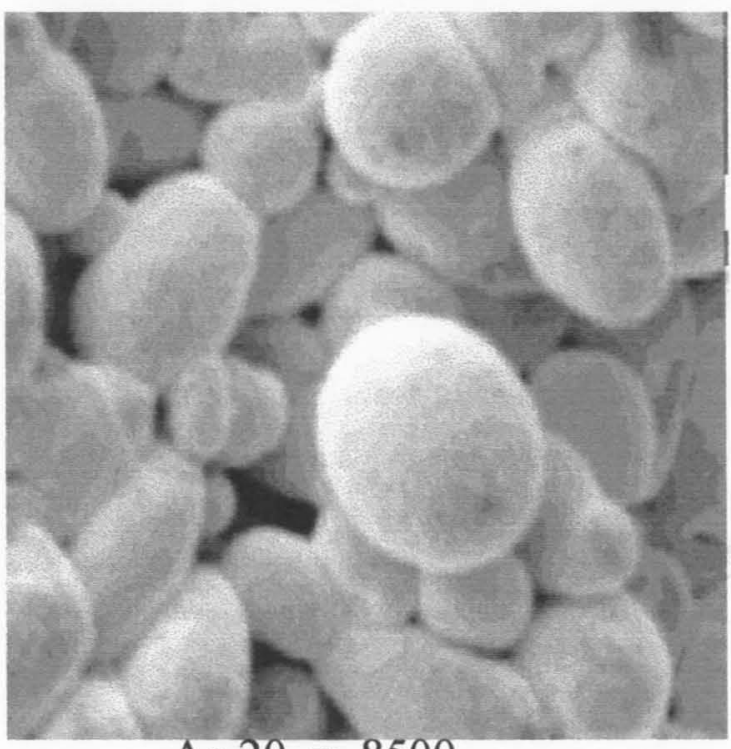

Ac $20 \times 8500$
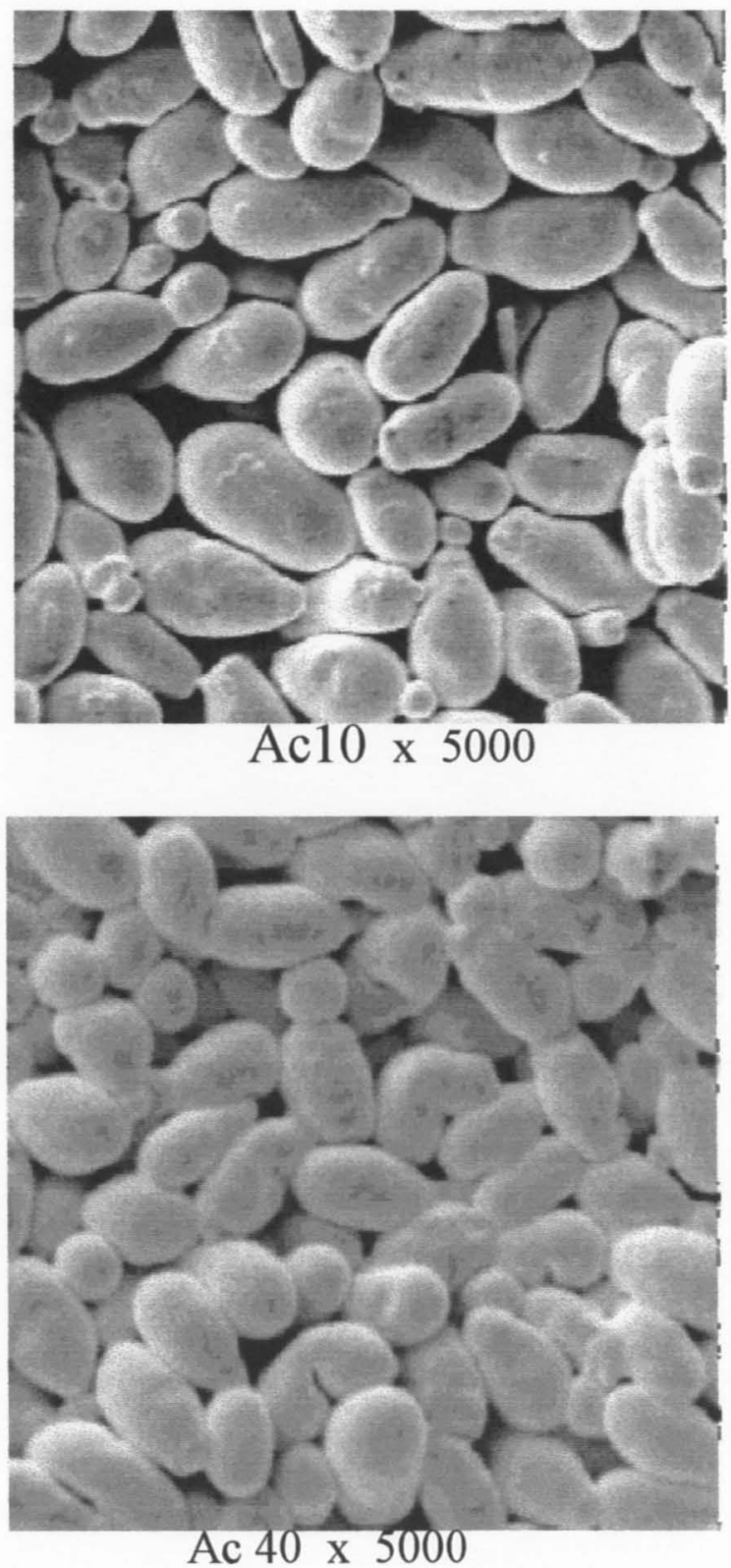

Figura 3 - Células de $S$. cerevisiae após contato com soluções à 5, 10, 20 e $40 \mathrm{mg} \mathrm{L}^{-1}$ de acetato de cádmio por 16 horas à $26-28^{\circ} \mathrm{C}$. Ac seguido de número $=$ concentração do metal na solução $\mathrm{x}$ seguido de número = aumento empregado na microscopia eletrônica por varredura. 

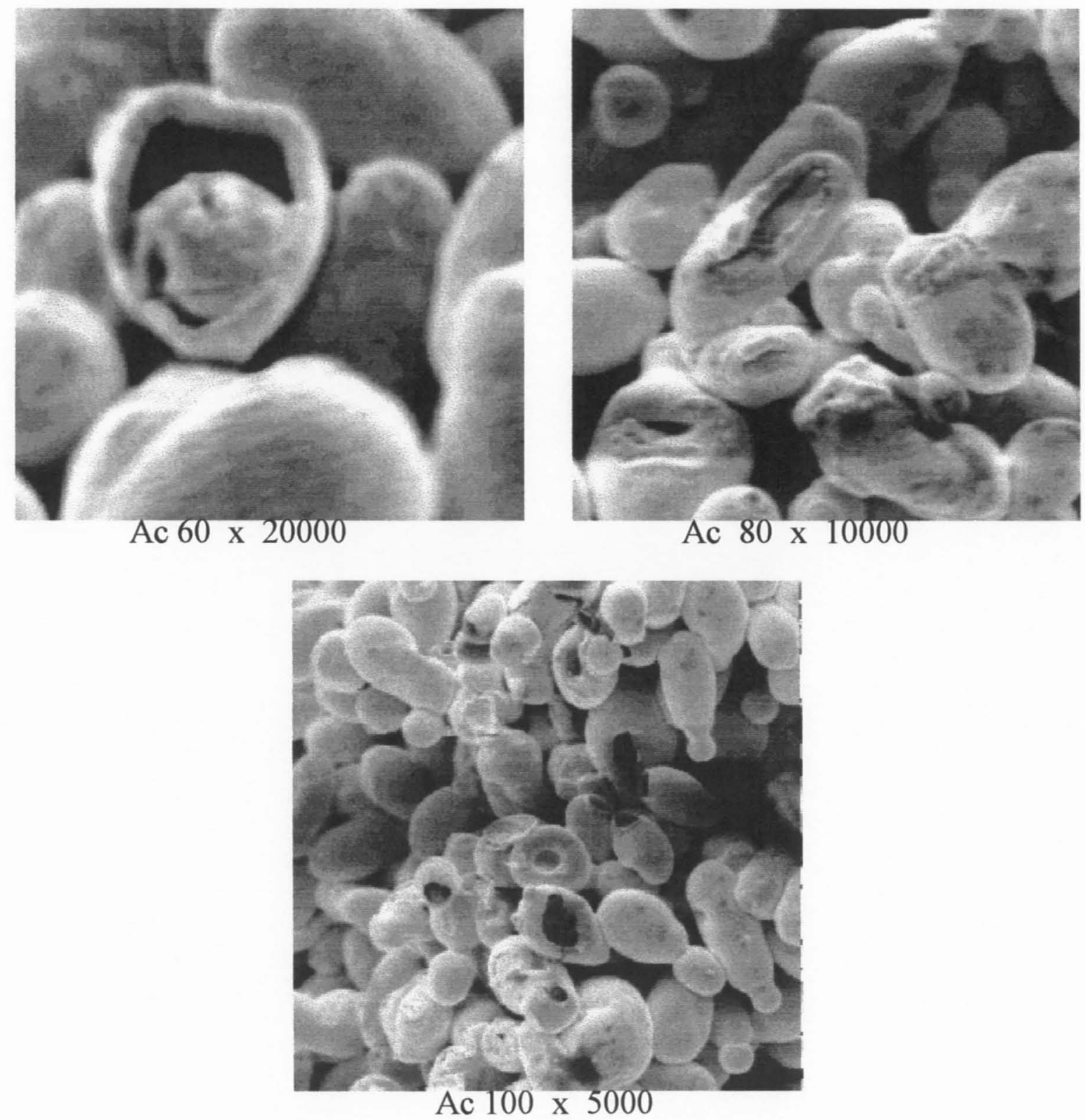

Figura 4 - Células de $S$. cerevisiae após contato com soluções à 60,80 e $100 \mathrm{mg} \mathrm{L}^{-1}$ de acetato de cádmio por 16 horas à $26-28{ }^{\circ} \mathrm{C}$. Ac seguido de número = concentração do metal na solução x seguido de número = aumento empregado na microscopia eletrônica por varredura. 


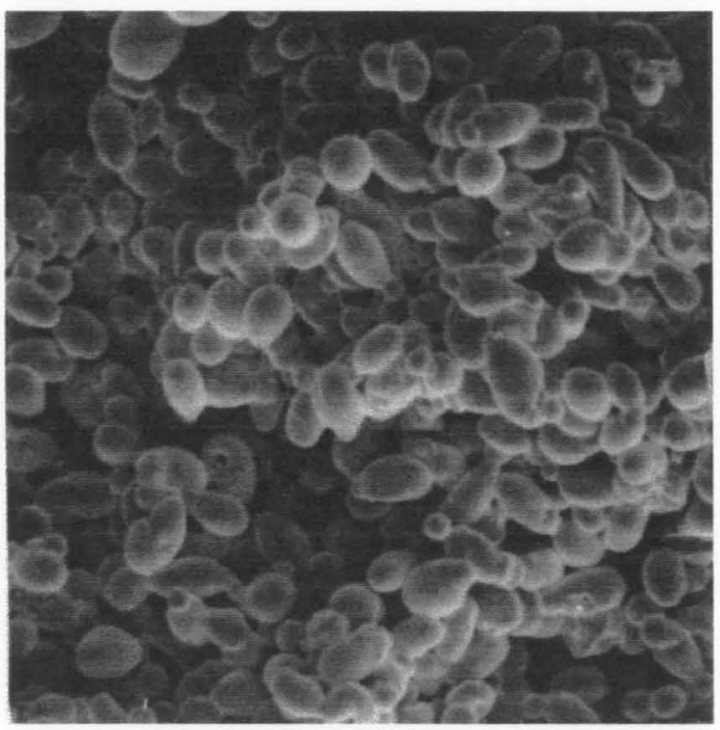

$\mathrm{Cl} 5 \times 5000$

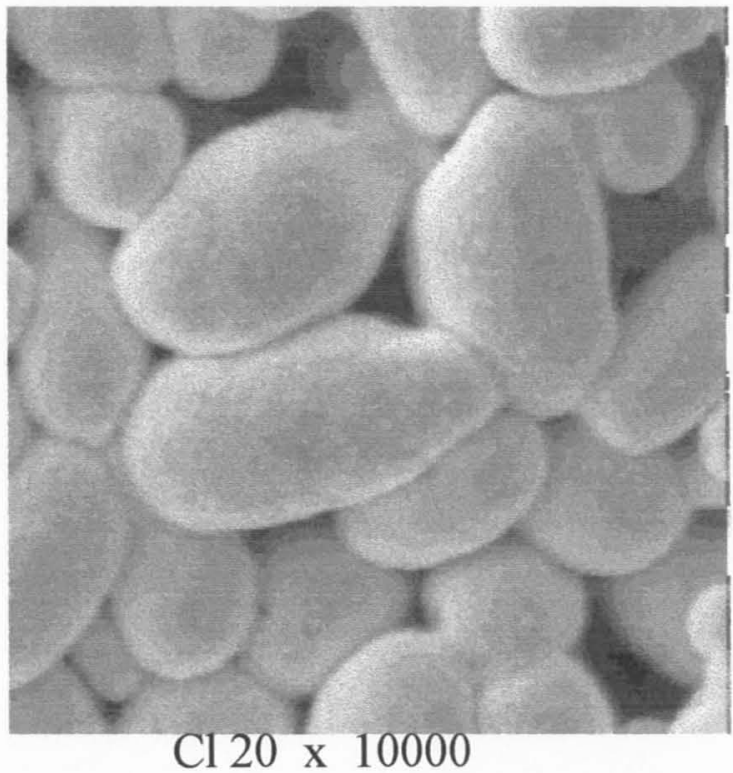

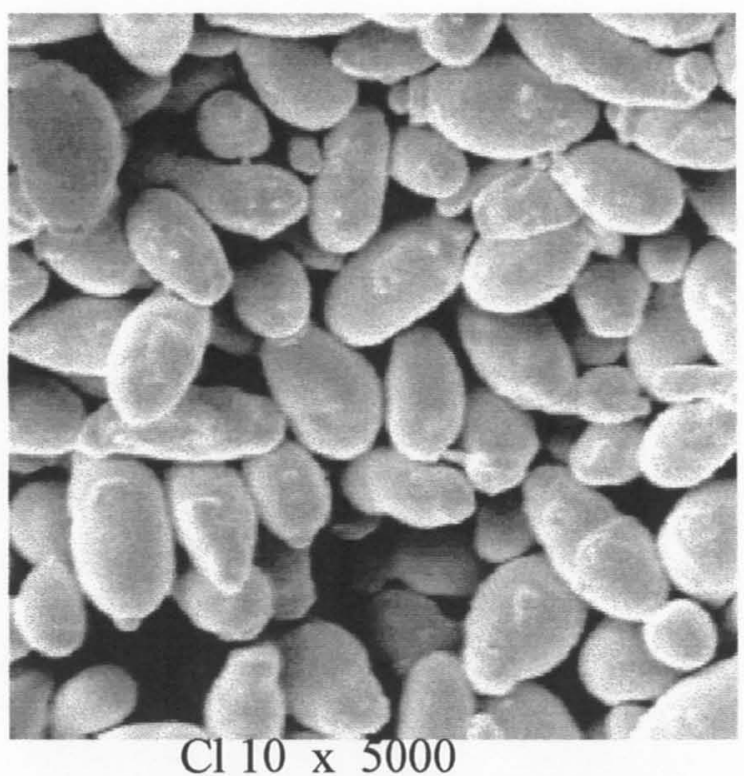

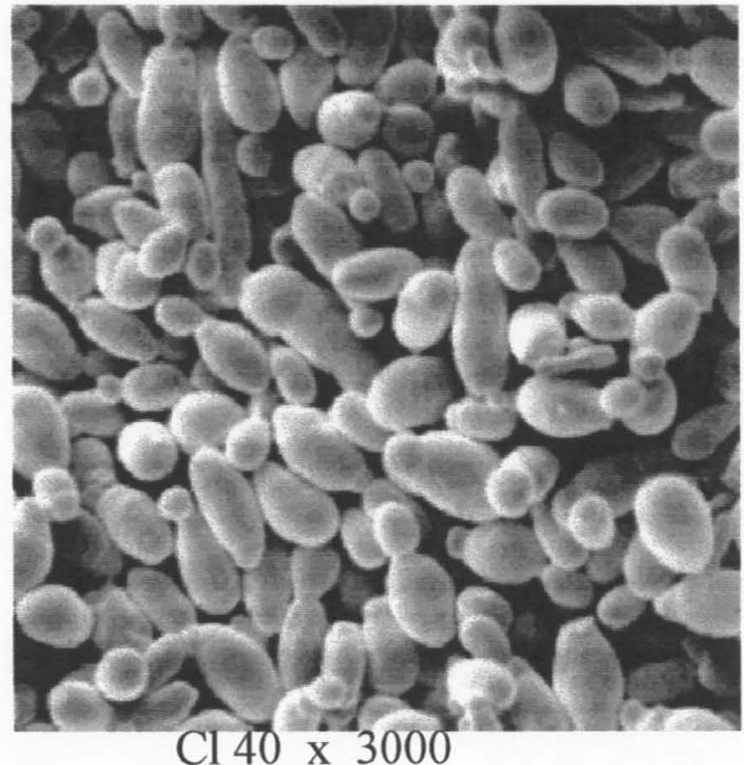

Figura 5 - Células de $S$. cerevisiae após contato com soluções à $5,10,20$ e $40 \mathrm{mg} \mathrm{L}^{-1}$ de cloreto de cádmio por 16 horas à $26-28{ }^{\circ} \mathrm{C}$. $\mathrm{Cl}$ seguido de número = concentração do metal na solução $\mathrm{x}$ seguido de número = aumento empregado na microscopia eletrônica por varredura 

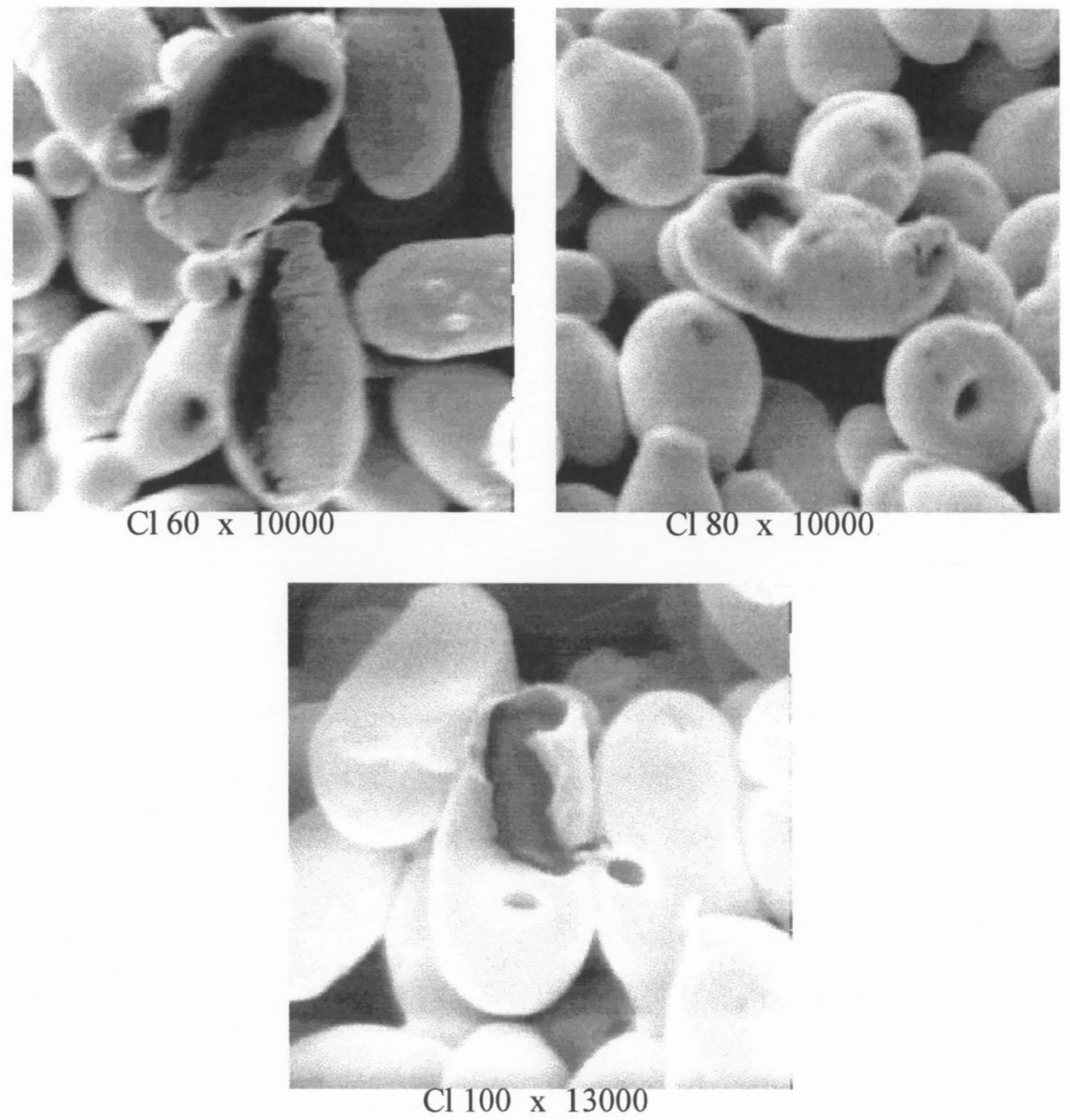

Figura 6 - Células de $S$. cerevisiae após contato com soluções à 60,80 e $100 \mathrm{mg} \mathrm{L}^{-1}$ de cloreto de cádmio por 16 horas à $26-28{ }^{\circ} \mathrm{C} . \mathrm{Cl}$ seguido de número $=$ concentração do metal na solução x seguido de número = aumento empregado na microscopia eletrônica por varredura 

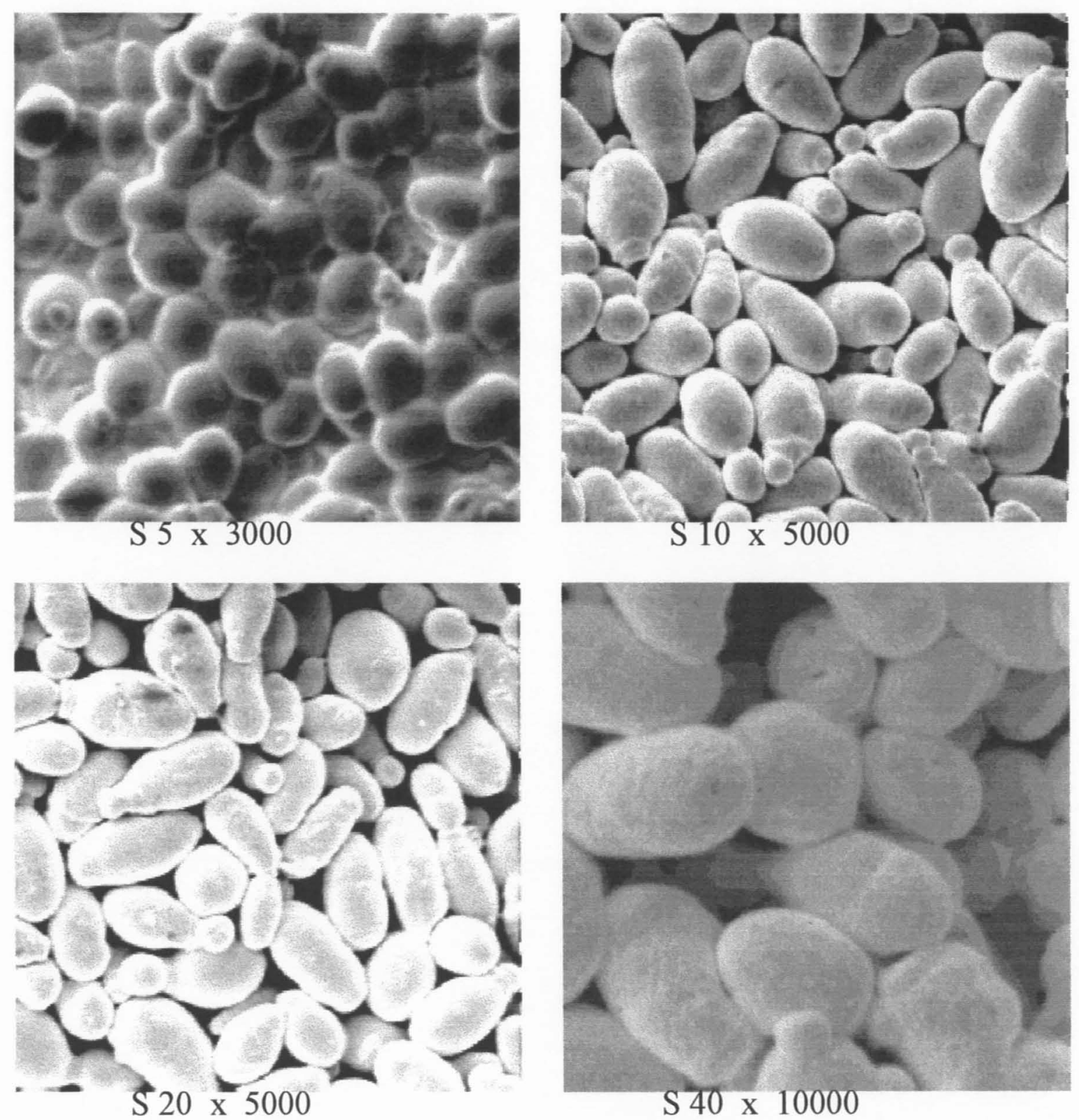

Figura 7 - Células de $S$. cereviisiae após contato com soluções à 5, 10, 20 e $40 \mathrm{mg} \mathrm{L}^{-1} \mathrm{de}$ sulfato de cádmio por 16 horas à $26-28{ }^{\circ} \mathrm{C}$. $\mathrm{S}$ seguido de número $=$ concentração do metal na solução $\mathrm{x}$ seguido de número = aumento empregado na microscopia eletrônica por varredura 

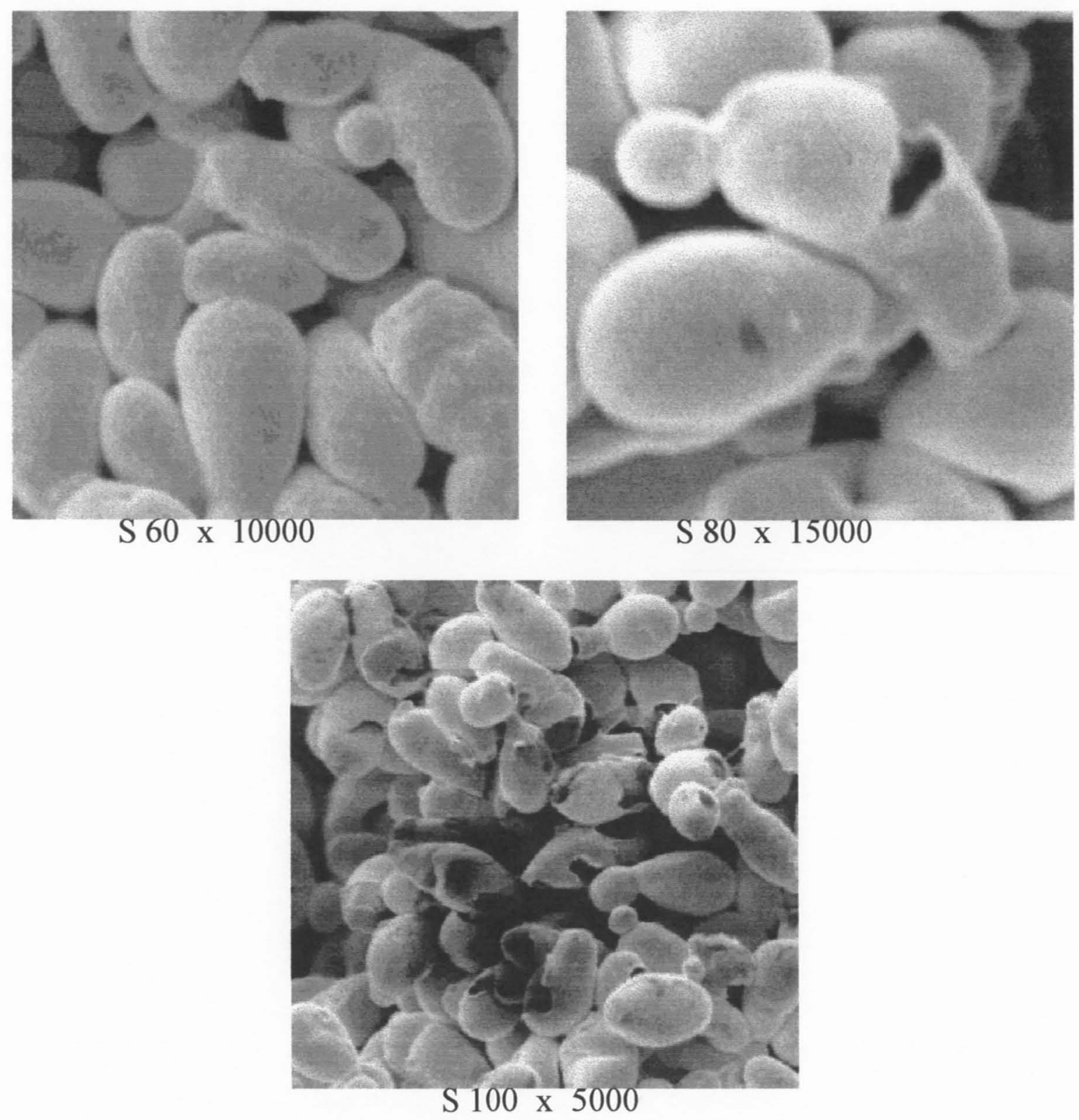

Figura 8 - Células de $S$. cerevisiae após contato com soluções à 60,80 e $100 \mathrm{mg} \mathrm{L}^{-1}$ de sulfato de cádmio por 16 horas à $26-28{ }^{\circ} \mathrm{C}$. $\mathrm{S}$ seguido de número = concentração do metal na solução $\mathrm{x}$ seguido de número $=$ aumento empregado na microscopia eletrônica por varredura. 

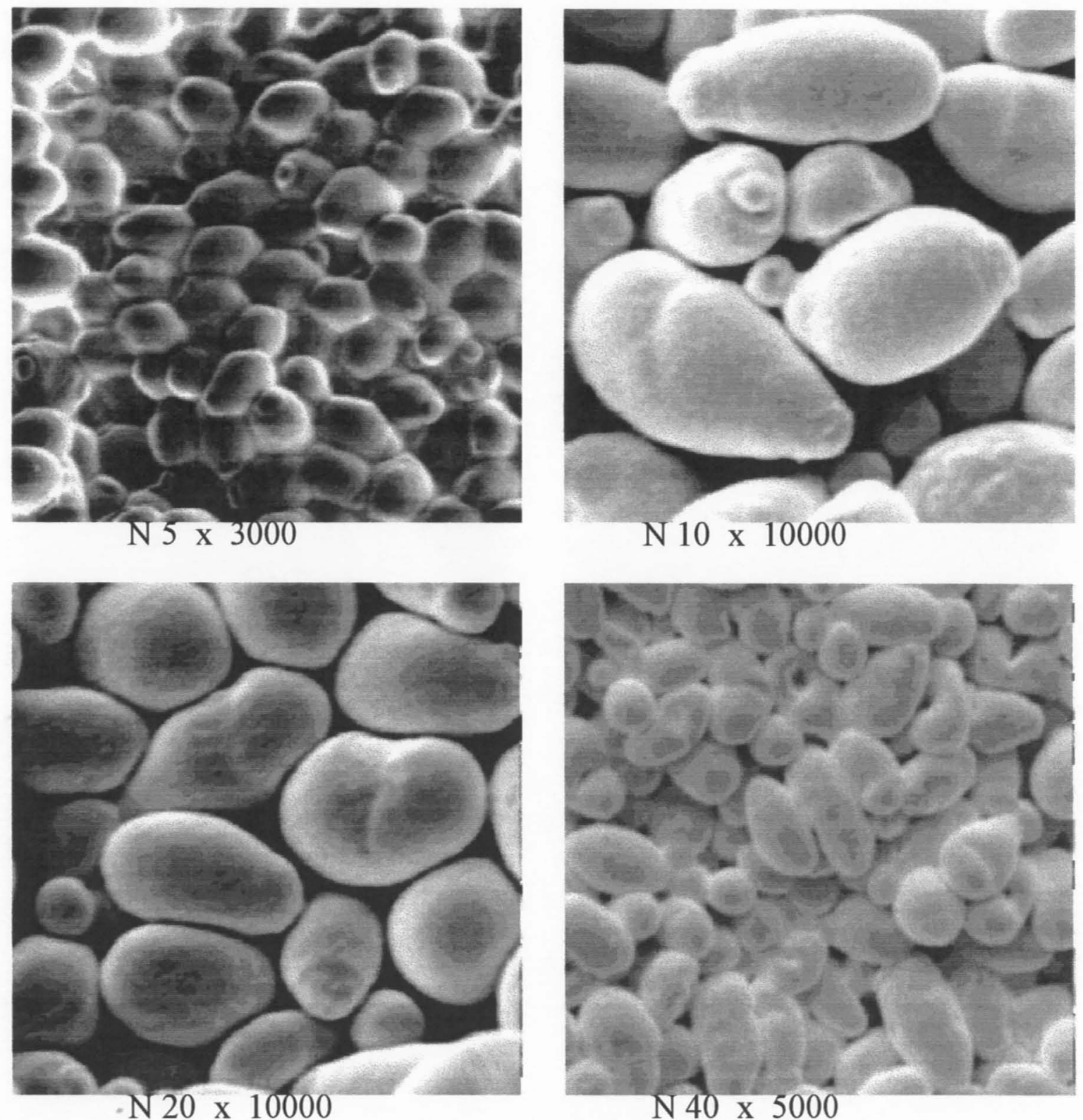

Figura 9 - Células de $S$. cerevisiae após contato com soluções à 5, 10, 20 e $40 \mathrm{mg} \mathrm{L}^{-1}$ de nitrato de cádmio por 16 horas à $26-28{ }^{\circ} \mathrm{C}$. $\mathrm{N}$ seguido de número $=$ concentração do metal na solução. $\mathrm{x}$ seguido de número = aumento empregado na microscopia eletrônica por varredura 

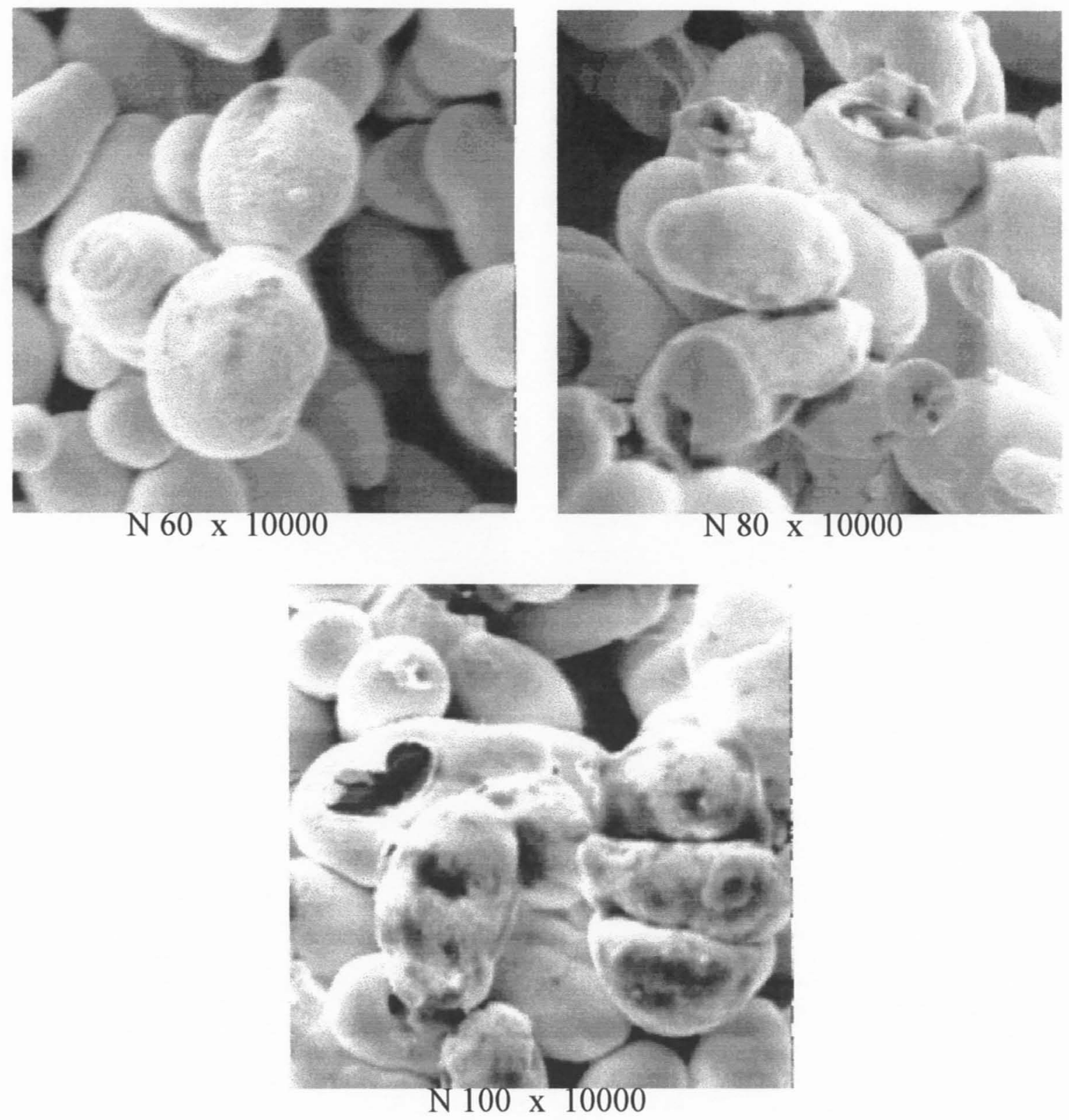

Figura 10 - Células de $S$. cerevisiae após contato com soluções à 60,80 e $100 \mathrm{mg} \mathrm{L}^{-1}$ de nitrato de cádmio por 16 horas à $26-28{ }^{\circ} \mathrm{C}$. $\mathrm{N}$ seguido de número $=$ concentração do metal na solução. $\mathrm{x}$ seguido de número $=$ aumento empregado na microscopia eletrônica por varredura 
Os perfis semelhantes das isotermas de adsorção do cádmio nos quatro diferentes sais, com diminuição na quantidade de metal acumulado a partir de $60 \mathrm{mg} \mathrm{L}^{-1}$ na solução de contato pode ser compreendido a vista das microfotografias feitas nas células após cada experimento - Figuras 2 a 10.

As microfotografias mostram claramente danos nas paredes celulares, os quais não são sempre acompanhadas de igual dano às membranas citoplasmáticas.

O fato de células, expostas a concentrações acima de $40 \mathrm{mg} \mathrm{L}^{-1}$, como entidades fisiológicas funcionais estarem danificadas e nestas condições acumularem menos cádmio possibilita inferir, parte do metal acumulado até as doses de $40 \mathrm{mg} \mathrm{L}^{-1}$ não o foi apenas por adsorção às paredes celulares, e, sim, também, por absorção ativa com emprego de energia pelas células.

Embora as células danificadas acima da concentração de $40 \mathrm{mg} \mathrm{L}^{-1}$ - Figuras 4, 6, 8 e 10 - não estejam vivas e funcionais, suas paredes continuam presentes na solução de contato. Ora, se as paredes celulares estão presentes e, se fossem as mesmas as únicas responsáveis pelo acúmulo de cádmio via adsorção, a concentração do metal, na solução de contato, deveria variar pouco, se o metal acumulado o tivesse sido apenas por adsorção às paredes.

Portanto, fica comprovado que até a dose de $40 \mathrm{mg} \mathrm{L}^{-1}$ na solução de contato, nos experimentos realizados, parte do metal acumulado o foi no interior das células de levedura. Entretanto a quantificação da contribuição individual dos fenômenos de adsorção e de absorção para acúmulo de cádmio pela levedura, nas condições experimentais, não pode ser determinada com exatidão.

Devido ao longo tempo de contato, não pode ser determinado se menores tempos de contato seriam menos prejudiciais às células, mesmo nas concentrações mais elevadas onde, no presente estudo, foram constatados danos irreversíveis nas paredes celulares. 


\section{CONCLUSÕES}

Nas condições empregadas neste experimento,

Saccharomyces cerevisiae acumulou cádmio em quantidades crescentes até a concentração de $40 \mathrm{mg} \mathrm{L}^{-1}$ na solução de contato.

Os quatro sais de cádmio empregados mostraram-se altamente prejudiciais à integridade das células de levedura, em concentrações de $60 ; 80$ e $100 \mathrm{mg} \mathrm{L}^{-1}$.

Os sais empregados como fontes de cádmio - acetato, cloreto, sulfato e nitrato têm influência nos níveis de acúmulo do metal pelas células de levedura.

Até a concentração de $40 \mathrm{mg} \mathrm{L}^{-1}$ parte do metal acumulado o foi, por absorção, dentro das células e não apenas por adsorção às paredes das mesmas.

Assim, mediante as condições testadas na presente pesquisa sugerimos que as leveduras podem atuar como agentes de biosorção de metais contaminantes. 


\section{REFERÊNCIAS BIBLIOGRÁFICAS}

ADRIANO, D. C. Trace elements in the terrestrial environment. New York: SpringerVerlag, 1986. cap.4, p.105-155. Cadmium.

ALBERTS,B.; BRAY, D.; LEWIS, J. et al. Biologia Molecular da Célula. $3^{\text {a }}$ ed. Porto Algre; Artes Médicas, 1997. cap. 11, p. 507-549: Transporte trasnmembrana de moléculas pequenas e bases iônicas da excitabilidade da membrana.

ALLOWAY, B. J. Heavy metals in soils. New York: John Wiley, 1993. 339p.

BRADY,D; ROSE, P. D.; DUNCAN, J. R. The use of hollow fiber cross-microfiltration in bioaccumulation and continuous removal of heavy metals from solution by Saccharomyces cerevisiae. Biotechnology \& Bioengineering, v.44, n.11, p.13621366, 1994.

BRADY, D.; DUNCAN, J. R. Bioacumulation of metal cations by Saccharomyces cerevisiae. Applied Microbiology and Biotechnology, v.41, n.1, p.149-154, 1994.

COKER, E. G.; MATTHEWS, P. J. Metals in sewage slude and their potencial effects in agriculture. Water Science and Technology, v.15, p.209-225, 1983.

COLLINS, Y. E.; STOTZKY, G. Heavy metals alter the eletrokinetic properties of bacteria, yeasts, and clay minerals. Applied and Environmental Microbiology, v. 58, n.5, p. $1592-1600,1992$. 
COOKE, J. A. ; JOHNSON, M. S. Cadmium in small mammals. In: In: BEYER, W. N.; HEINZ, G. H.; REDMON-NORWOOD, A. W. Environmental contaminants in wildlife. Boca Raton: CRC Press, 1996. cap.16, p. 377-388

ELPO, E. R. S.; FREITAS, R. J. S. Avaliação de teores de cádmio, chumbo, cromo e níquel nos alimentos da cesta básica. Boletim do Centro de Pesquisa e Processamento de Alimentos, v. 13, n.2, p.71-84, 1995.

FAO/WHO. Food Standards Programme. codex commitee on food additives and contaminants. Guideline levels for cadmium and lead in food. Rome, 1989. 4p. (CX/FAC 90/18)

FERNANDEZ, J. C.; ROSES, O. E. Resíduos de metales toxicos en alimentos. In: SEMINÁRIO LATINO AMERICANO SOBRE TOXICOLOGIADE ALIMENTOS Campinas, 1983. Anais. Campinas: UNICAMP, 1983, p.94-112.

FUKUSHI, K.; CHANG, D.; GHOSH, S. et al. Enhanced heavy metal uptake by activated sludge culture grown in the pressure of biopolymer estimulatore. Water Science and Technology, v.34, n.5/6, p.267-272, 1996./ Resumo n.4065-A32 em Industrial \& Applied Microbiology, v.32, n. 6, p.108, June 1997/

GADD, G. M.; MOWLL, J. L. The relationship between cadmium uptake, potassium release and viability in Saccharomyces cerevisiae. FEMS Microbiology Letters, v. 16, n. 1, p. $45-48,1983$.

GARCIA, C.; HERNANDEZ, T.; COSTA, F. The influence of comporting and naturation process on the heavy metal extractability from some organic wast. Biological Wastes, v.31, p.291-301, 1990.

GERHARDSSON, L.; SKERFVING, S. Concepts on biological markers and biomonitoring for mMetal toxicity. In: CHANG, L. W. (Ed.) Toxicology of metals. Boca Raton: CRC Press, 1996. cap.6, p.81-112.

GOMES, F. P. Estatística experimental. $13^{0}$ ed. Piracicaba: ESALQ, 1990. 468 p. 
HALÁSZ, A.; LÁSZTITY, R. Use of yeast biomass in food production. Boca Raton: CRC , 1991a, cap.5, p.115-189. Extration of yeast proteins: yeast protein concentrates and isolates.

HALÁSZ, A.; LÁSZTITY, R. Use of yeast biomass in food production. Boca Raton: CRC, 1991b. cap.6, p.193-195: Introduction.

HOLAN, Z. R.; VOLESKY, B. Biosorption of lead and nickel by biomass of marina algae. Biotechnology \& Bioengineering, v. 43, n.11, p.1001-1009, 1994.

IMHOFF, K; IMHOFF, K. R. Manual de tratamento de águas residuais: dimencionamento e planejamento das estações de tratamento de esgotos. 26 ed. São Paulo: Editora Edgard Blücher, 1986. cap.2, p.22 - 214.

JARDIM, W. F. Metais pesados um dano irreparável. Revista Brasileira de Tecnologia, v.14, n.2, p.41-45, 1983.

KITAJIMA, E. W. Curso introdutório de microscopia eletrônica de varredura. Piracicaba: ESALQ - USP, 1997. 37 p.

KLIS, F. M. Review: cell wall assembly in yeast. Yeast, v.10, n.7, p.851-869, 1994.

LAW, R. J. Metals in marine mammals. In: BEYER, W. N.; HEINZ, G. H.; REDMONNORWOOD, A. W. Environmental contaminants in wildlife. Boca Raton: CRC Press, 1996. cap. 15, p.357-376.

LODDER, J. ; DEL LEY, L. The Yeast. Amsterdam: North Holland, 1971. p. 448-457.

MACÊDO, J. A. B. Sistema especialista para controle e tratamento de água na indústria de alimentos. Viçosa, 1995. 93p. Dissertação (Mestrado) - Universidade Federal de Viçosa. 
MARTIN, T. D.; CREED, J. T.; LONG, S. E. Sample preparation procedure for spectrochimical determination of total recoverable elements. In: Methods for the determination of metals in environmental samples. BOCA RATON: SMOLEY, C. K., 1992. cap.2. p. 15-24.

MATIS, K. A.; ZOUBOULIS, A. I. Flotation of cadmium-loaded biomass. Biotechnology \& Bioengineering, v.44, n.3, p.354-360, 1994.

MATTIAZZO-PREZOTTO, M. E. Comportamento de cobre, cádmio, crômio, níquel e zinco adicionados à solos de clima tropical em diferentes valores de $\mathrm{pH}$. Piracicaba, 1994. 197p. Tese (Livre-Docência), Escola Superior de Agricultura "Luiz de Queiroz", Universidade de São Paulo.

MORAES, S. A.; ALVES, S. B. Quantificação de inóculo de patógenos de insetos. In: ALVES, S. B. Controle microbiano de insetos. São Paulo: Editora Manole, 1986. cap. 14, p.278-288.

MULLER, M.; ANKE, M.; HARTMANN. E.; ILLING-GUNTHER, H. Oral cadmium exposure of adults in germany. 1: Cadmium content of foodstuffs and beverages. Food Additives and Contaminants, v.13, n.3, p.359-378, 1996.

NAKAJIMA, A.; SAKAGUCHI, T. Selective acumulation of heavy metals by microrganisms. Applied Microbiology and Biotechnology, v.24, n.1, p.59-64, 1986.

NATANSOHN, S.; ROURKE, W. J.; LAI, W. C. Recovery of valuable metals from industrial wastes. In: VANDERGRIFT, G. F.; REED, D. T.; TASKER,I. R. Environmental remediation. Washington: American Chemical Society, 1992. cap. 10, p.129-146. (ACS Symposium Series 509)

NOBEL, J. G.; KLIS, F. M.; MUNNIK, T. et al. An assay of relative cell wall porosity in Saccharomyces cerevisiae, Kluyveromyces lactis and Schizosaccharomyces pombe. Yeast, v.6, n.6, p.483-490, 1990. 
NOGAWA, K.; KIDO, T. Itai-Itai disease and health effects of cadmium. in CHANG, L. W. Toxicology of metals. Boca Raton: CRC Press, 1996. cap.21, p.353-369.

OMAR, N. B ; MERROUN, M. L.; MUNOZ, M. T.; ARIAS, J. M. Brewery yeast as a biosorbent for uranium. Journal of Applied Bacteriology, v.81, n.3, p.283-287, 1996./ Resumo em FSTA Abstracts on CD-ROM, 1996-1997/

ORGANIZAÇÃO ANDREI EDITORA. Vigilância Sanitária. Coletânea de atos em vigor pertinentes à atual legislação sanitária: de drogas, medicamentos, insumos farmacêuticos, produtos de higiene, cosméticos, perfumes e saneantes domissanitários e de portos, aeroportos e fronteiras. São Paulo:Organização Andrei, 1979. v.2.

PACYNA, J. M. Monitoring and assessment of metal contaminants in the air. In: CHANG, L. W. Toxicology of metals. Boca Raton: CRC Press, 1996. cap.1, p.9-28.

PELCZAR Jr., M. J.; CHAN, E. C. S.; KRIEG, N. R. Microbiologia: Conceitos e Aplicações. 2 ed., São Paulo: Makron Books, 1997a. v.1, cap.4, p.100-143. Estrutura das células eucarióticas e procarióticas.

PELCZAR Jr., M. J.; CHAN, E. C. S.; KRIEG, N. R. Microbiologia: conceitos e aplicações. 2.ed., São Paulo: Makron Books, 1997b. v.1, cap. 2, p.52-74. Objetivos da microbiologia.

PEREIRA, J. C. Avaliação da contaminação do meio ambiente por metais pesados na região do Vale do Aço (MG). Viçosa, 1995. 117p. Dissertação (Mestrado) Universidade Federal de Viçosa.

RAMMHOLDT, T.; FISHER, P.; BUCHHOLZ, R. Heavy metals in destillery effluents and studies on their elimination. Branntweinwirtschaft. v.134, n.8, p.115-119, 1994/ Resumo em FSTA Abstracts on CD-ROM, 1995-1996/

REILLY, C. Metal contamination of food. London: Elsevier Applied Science, 1991. cap.6, p.131-151: Mercury and cadmium. 
ROBARDS, K.; WORSFOLD, P. Cadmium: toxicology and analysis. Analyst. v.116, n.6, p.549-568, 1991.

SANDHU, S. S. Trace element distribution in various phases of aquatic systems of the savannah river plant. In: VANDERGRIFT, G. F.; REED, D. T.; TASKER,I. R. Environmental remediation. Washington: American Chemical Society, 1992. cap.18, p.242-261. (ACS Symposium Series, 509)

SÃO PAULO (ESTADO). Lei, decretos, etc. Lei $n^{\circ} 997$ de 31 de maio de 1976. Diário Oficial, 08 de setembro de 1976. Seção I, p. 460-507. Dispõe sobre a prevenção e o controle da poluição do meio ambiente

SCHINDLER, P. W. The regulation of heavy metal concentrations in natural aquatic systems In: VERNET, J. P. Heavy metals in the environment. Amsterdam: Elsevier, 1991. cap. 4, p.95-124. ( Trace Metals in the Environment, 1)

SILVA, D. J. Análise de alimentos (métodos químicos e biológicos). Viçosa: Universidade Federal de Viçosa, Imprensa Universitária, 1990a, cap.1, p.1-11: Conceitos gerais sobre análise de alimentos e determinação da matéria seca.

TAVARES, T. M. Avaliação dos efeitos das emissões de cádmio e chumbo em Santo Amaro, Bahia. São Paulo, 1990. 274p. Tese (Doutorado) - Instituto de Química, Universidade de São Paulo.

TAVARES, T. M.; CARVALHO, F. M. Avaliação da exposição de populações humanas à metais pesados no ambiente: exemplos do Reconcavo Baiano. Química Nova, v.15, n.2, p.147-54, 1992.

TRINDADE, C. M. Precipitação de cromo por bactérias. Piracicaba, 1997, 47p. Dissertação (Mestrado) - Escola Superior de Agricultura "Luiz de Queiroz", Universidade de São Paulo.

VOLESKY, B. Biosorption of heavy metals. Boca Raton: CRC Press, 1990a. cap.1.1, p.3-6: Biosorption and biosorbents. 
VOLESKY, B. Biosorption of heavy metals. Boca Raton: CRC Press, 1990b. cap. 1.2, p.7-43: Removal and recovery of heavy metals by biosorption.

VOLESKY, B. ; MAY-PHILLIPS, H. A. Biosorption of heavy metals by Saccharomyces cerevisiae. Applied Microbiology and Biotechnology, v.42, n.5, p.797-806, 1995.

VOLESKY, B.; PRASETYO, I. Cadmium removal in a biosorption column. Biotechnology \& Bioengineering, v.43, n.11, p.1010-1015, 1994.

VOLESKY, B.; MAY-PHILLIPS, H. A.; HOLAN, Z. R. Cadmium biosorption by Saccharomyces cerevisiae. Biotechnology \& Bioengineering, v.41, p.826-829, 1993.

ZONTA, E. P.; MACHADO, A. A. SANEST 2: Sistema de Análise Estatística para Computadores. Piracicaba: SEI, 1992 (Softwear).

WHITE, C; GADD, G. M. Uptake and cellular distribuition of copper, cobalt and cadmium in strains of Saccharomyces cerevisiae cultured on elevated concentrations of these metals. FEMS Microbiology Ecology, v.38, n.5, p.277-283, 1986.

WOOD, J. M.; WANG, H. K. Microbial resistance to heavy metals. Environmental Science Technology, v.17, n.12, p.582-590, 1983. 
$A P \hat{E} N D I C E$ 

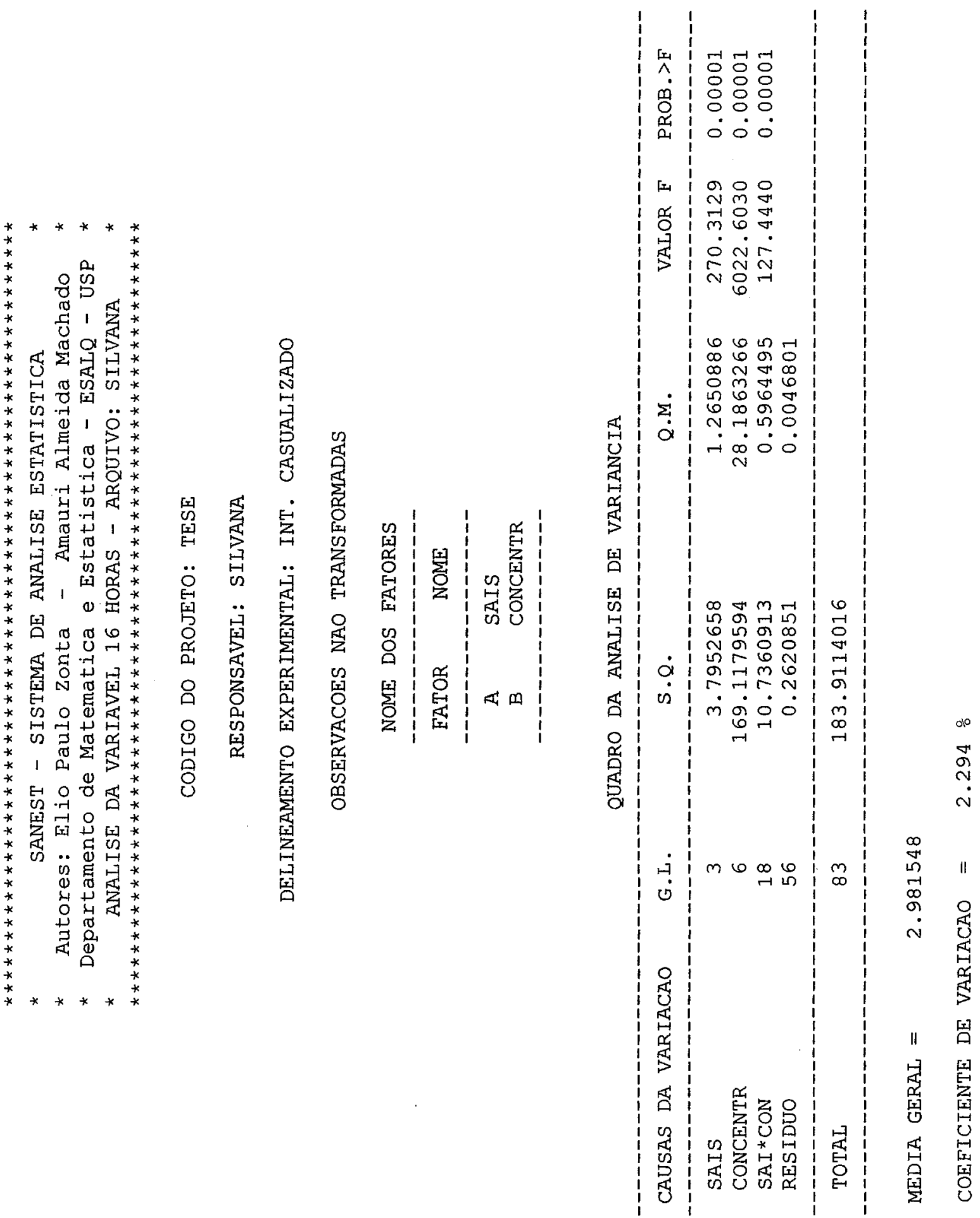

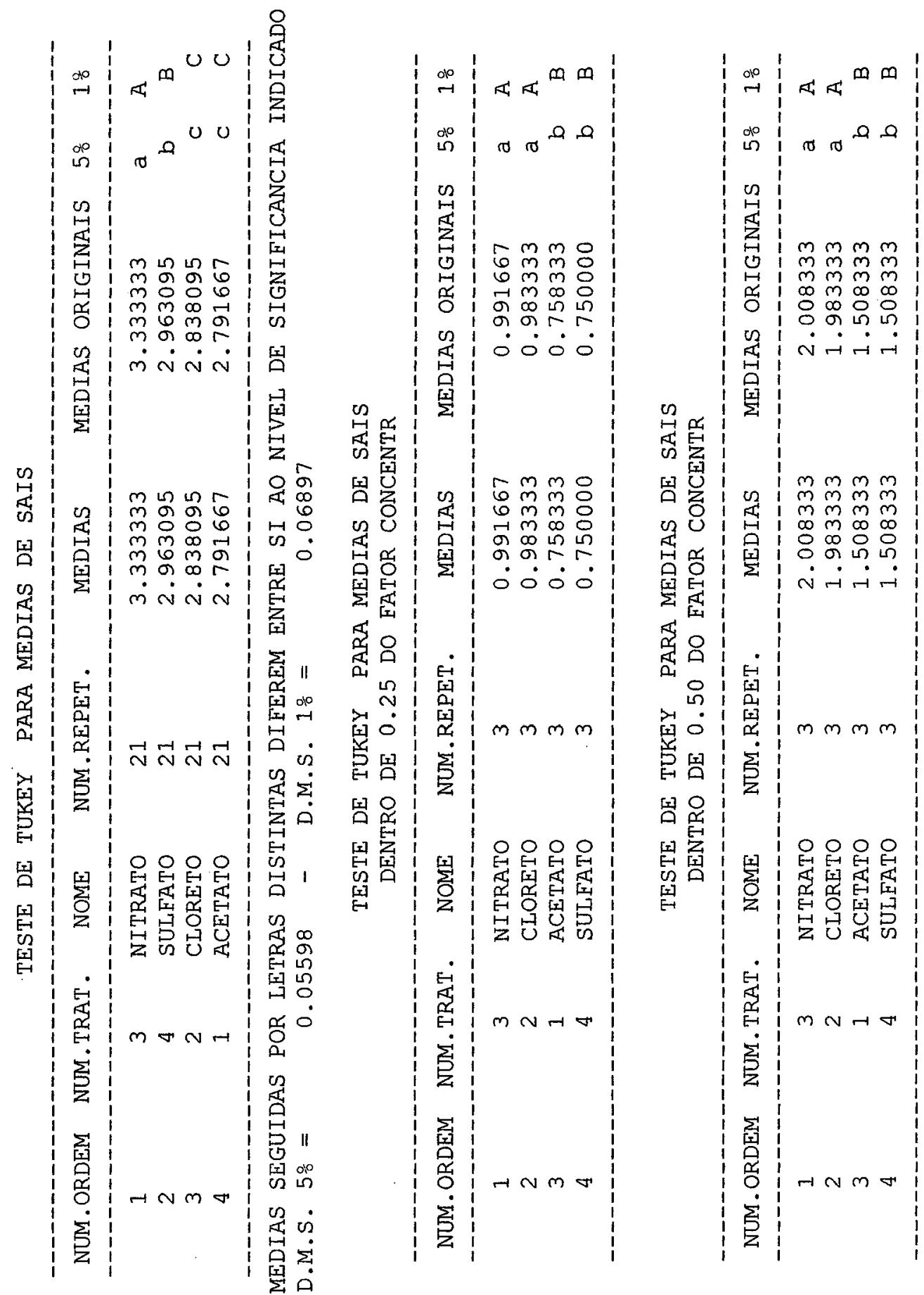

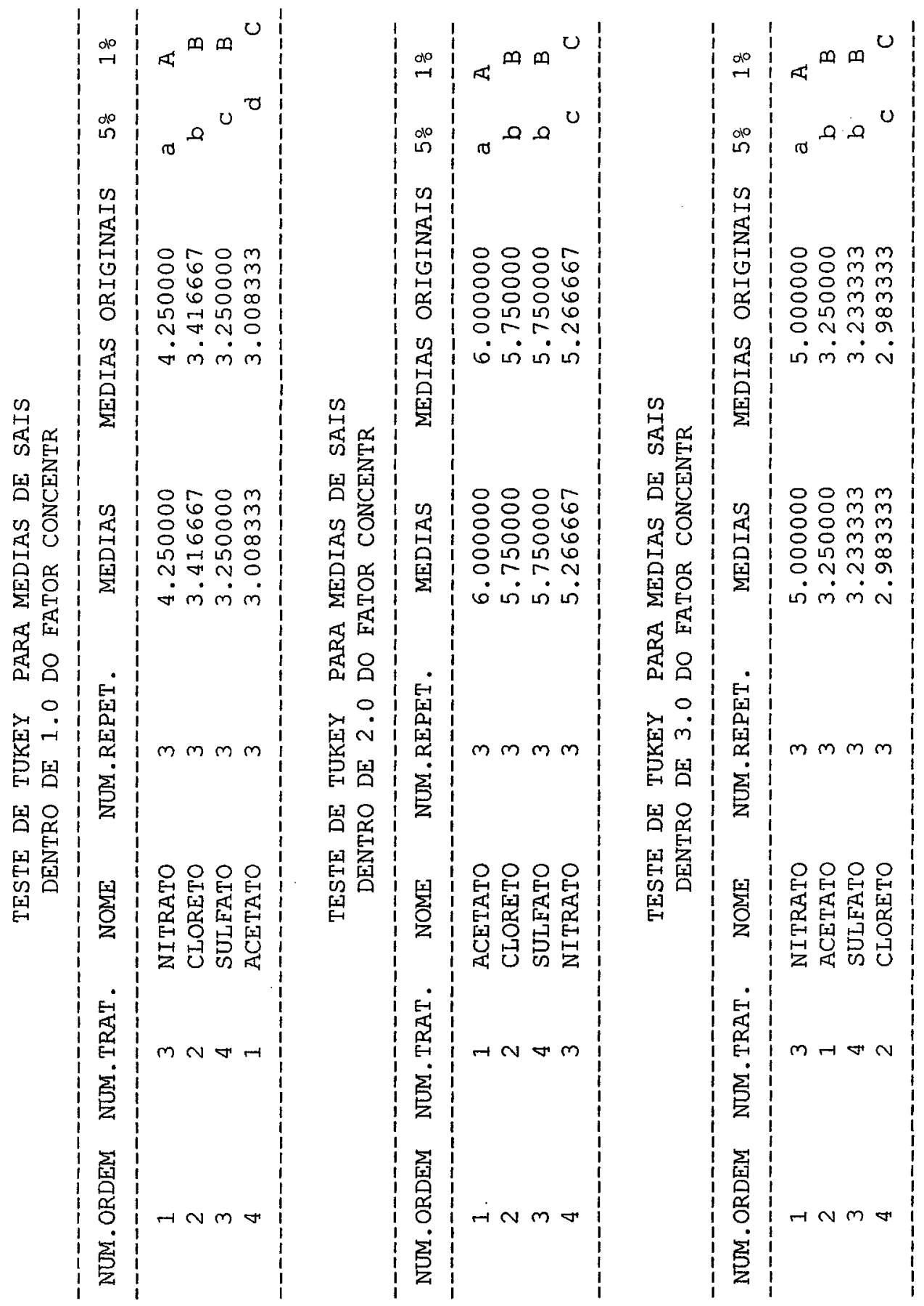


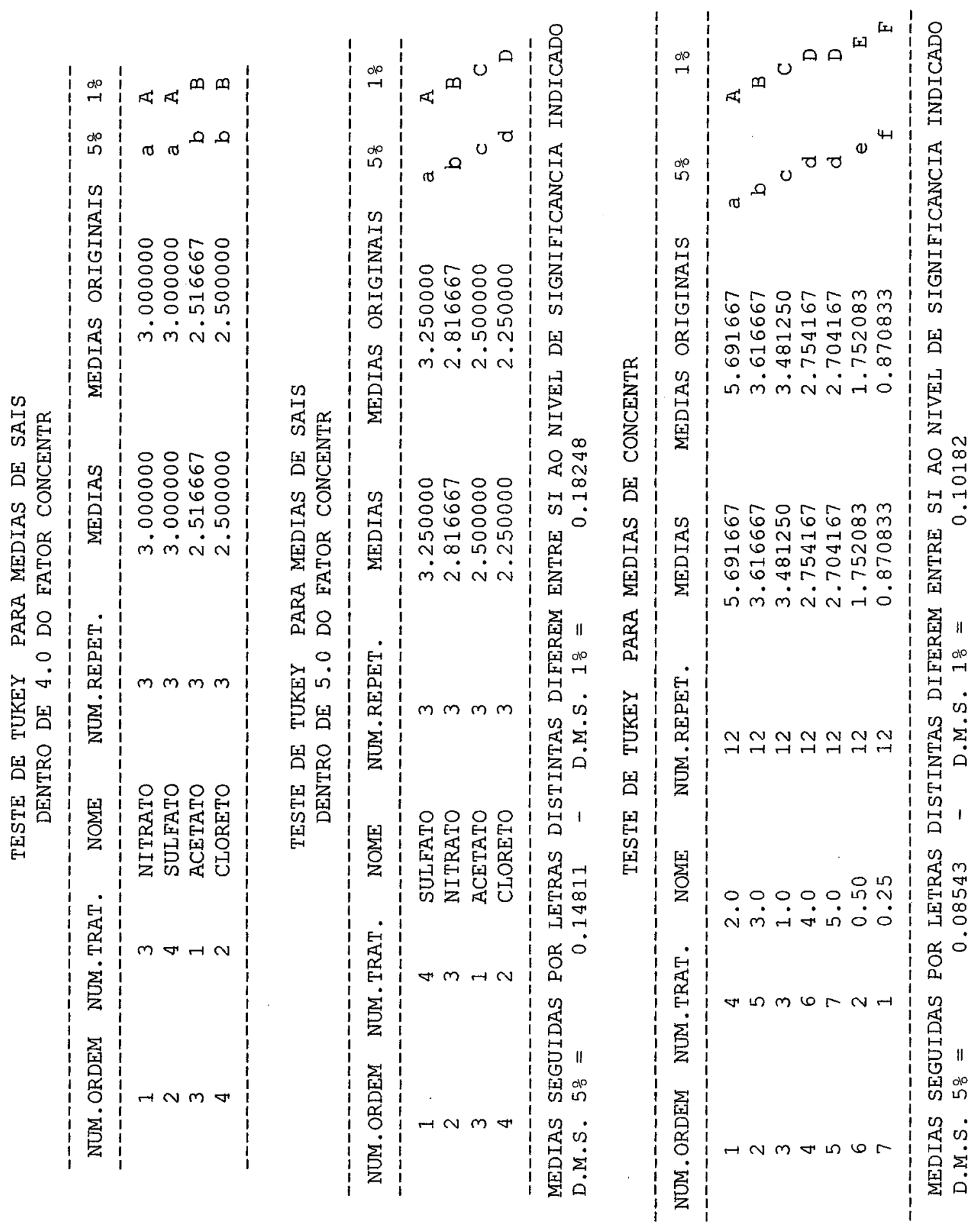



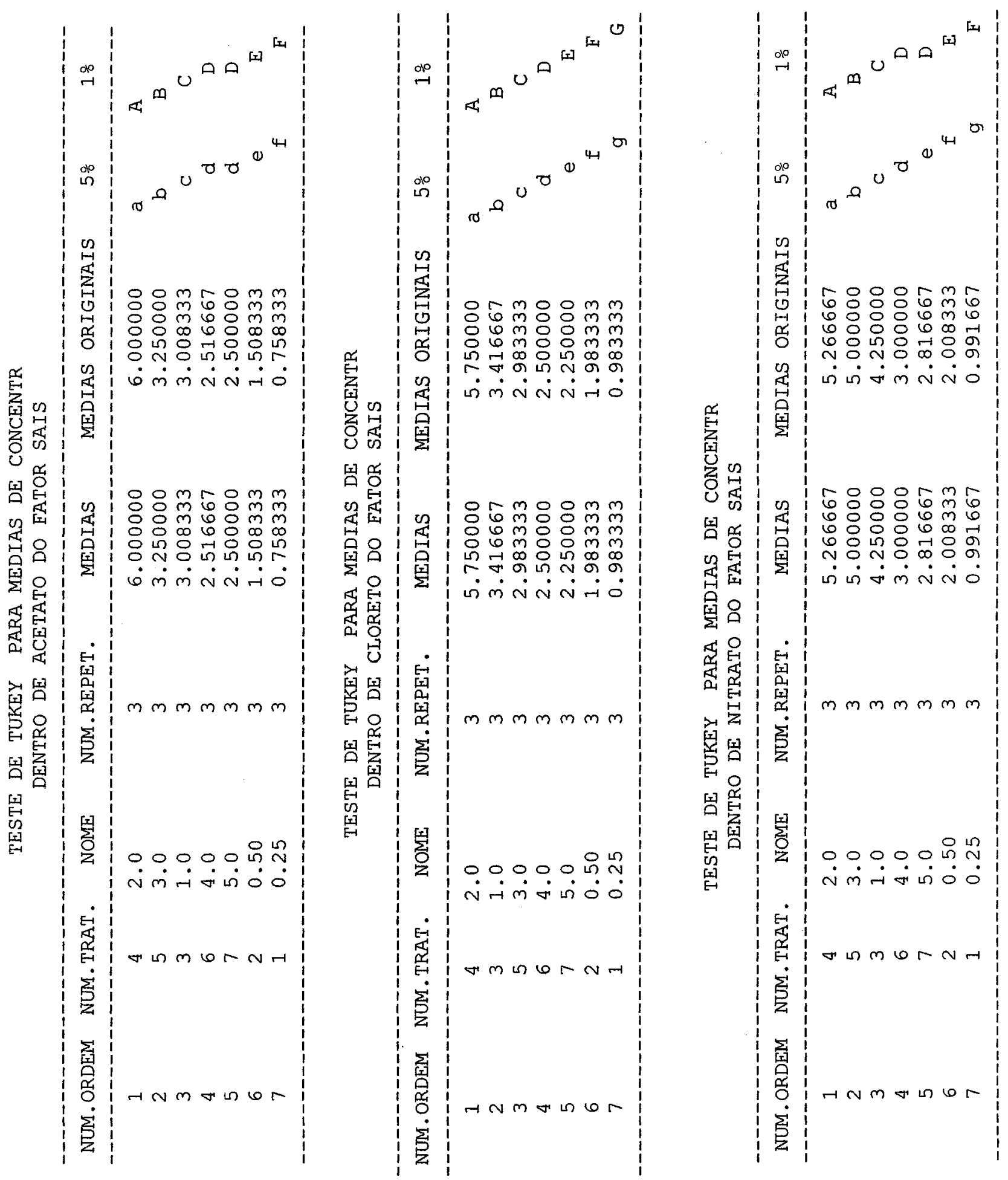


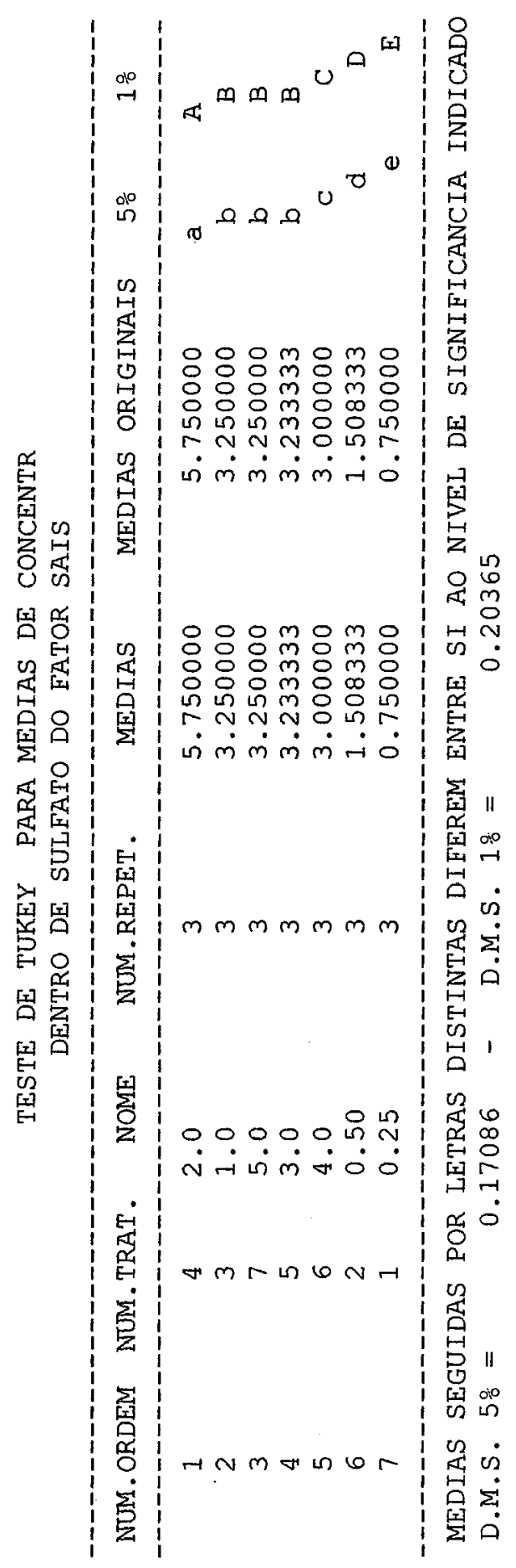

